\title{
WestVirginiaUniversity
}

THE RESEARCH REPOSITORY @ WVU

Graduate Theses, Dissertations, and Problem Reports

2011

\section{Variances in Diurnal Fatigue Patterns and Mood among Postpartum Women}

Amanda L. McBean

West Virginia University

Follow this and additional works at: https://researchrepository.wvu.edu/etd

\section{Recommended Citation}

McBean, Amanda L., "Variances in Diurnal Fatigue Patterns and Mood among Postpartum Women" (2011). Graduate Theses, Dissertations, and Problem Reports. 4752.

https://researchrepository.wvu.edu/etd/4752

This Thesis is protected by copyright and/or related rights. It has been brought to you by the The Research Repository @ WVU with permission from the rights-holder(s). You are free to use this Thesis in any way that is permitted by the copyright and related rights legislation that applies to your use. For other uses you must obtain permission from the rights-holder(s) directly, unless additional rights are indicated by a Creative Commons license in the record and/ or on the work itself. This Thesis has been accepted for inclusion in WVU Graduate Theses, Dissertations, and Problem Reports collection by an authorized administrator of The Research Repository @ WVU. For more information, please contact researchrepository@mail.wvu.edu. 
Variances in Diurnal Fatigue Patterns and Mood among Postpartum Women

Amanda L. McBean, B.S.

Thesis submitted to the Eberly College of Arts and Sciences at West Virginia University

in partial fulfillment of the requirements

for the degree of

Master of Science

in

Psychology

Hawley Montgomery-Downs, Ph.D., Chair

Miranda Reed, Ph.D.

Katherine Karraker, Ph.D.

Department of Psychology

Morgantown, West Virginia

2011

Keywords: postpartum, mothers, sleep, mood, circadian rhythm

Copyright 2011 Amanda L. McBean 


\section{ABSTRACT \\ Variances in Diurnal Fatigue Patterns and Mood among Postpartum Women}

\section{Amanda L. McBean}

Postpartum women have highly disrupted sleep and many experience a disruption in their circadian rhythm during this time. They are also susceptible to mood disruptions during the postpartum period. While mood disruption may be a result of sleep disruption, there are not many data to support a link between circadian rhythm disruption and mood among healthy postpartum women. This study sought to fill that gap. Participants were a convenience sample of 71 women from a larger study. The total sample was $26.4(S D=4.0)$ years old, had a mean annual income of $\$ 51,000(\mathrm{SD}=\$ 35,000)$, and had $15.7(\mathrm{SD}=2.9)$ years of education. All women were primiparous (first time mothers), $83.1 \%$ were married or cohabitating, $90.1 \%$ were white. Data used for these analyses were from postpartum weeks 2 and 12 . At each of these weeks, the women were categorized, based on variance across the day on fatigue reports, as having a significant diurnal rhythm or not. Overall, there were no differences in reported mood, stress, or anxiety levels between women with and without a diurnal rhythm at postpartum week 2. However, women with a rhythm at postpartum week 12 reported better $\operatorname{mood}(p=0.02, d=$ $0.62)$, lower levels of stress $(p=0.03, d=0.70)$, and less anxiety $(p=0.02, d=0.72)$ than women without a rhythm. In addition, women who were more morning-type were significantly more likely to have a circadian rhythm at both weeks $2(p=0.02)$ and $12(p=0.03)$ postpartum. Women who were older were also more likely to have a significant rhythm, but this difference was only found at week $12(p=0.05)$. The current study furthers knowledge of the benefits of maintaining a circadian rhythm during the postpartum period. It also establishes a novel way of evaluating and perhaps even intervening with women who might be at risk for postpartum mood, stress, or anxiety disorders. 


\section{TABLE OF CONTENTS}

TITLE PAGE .

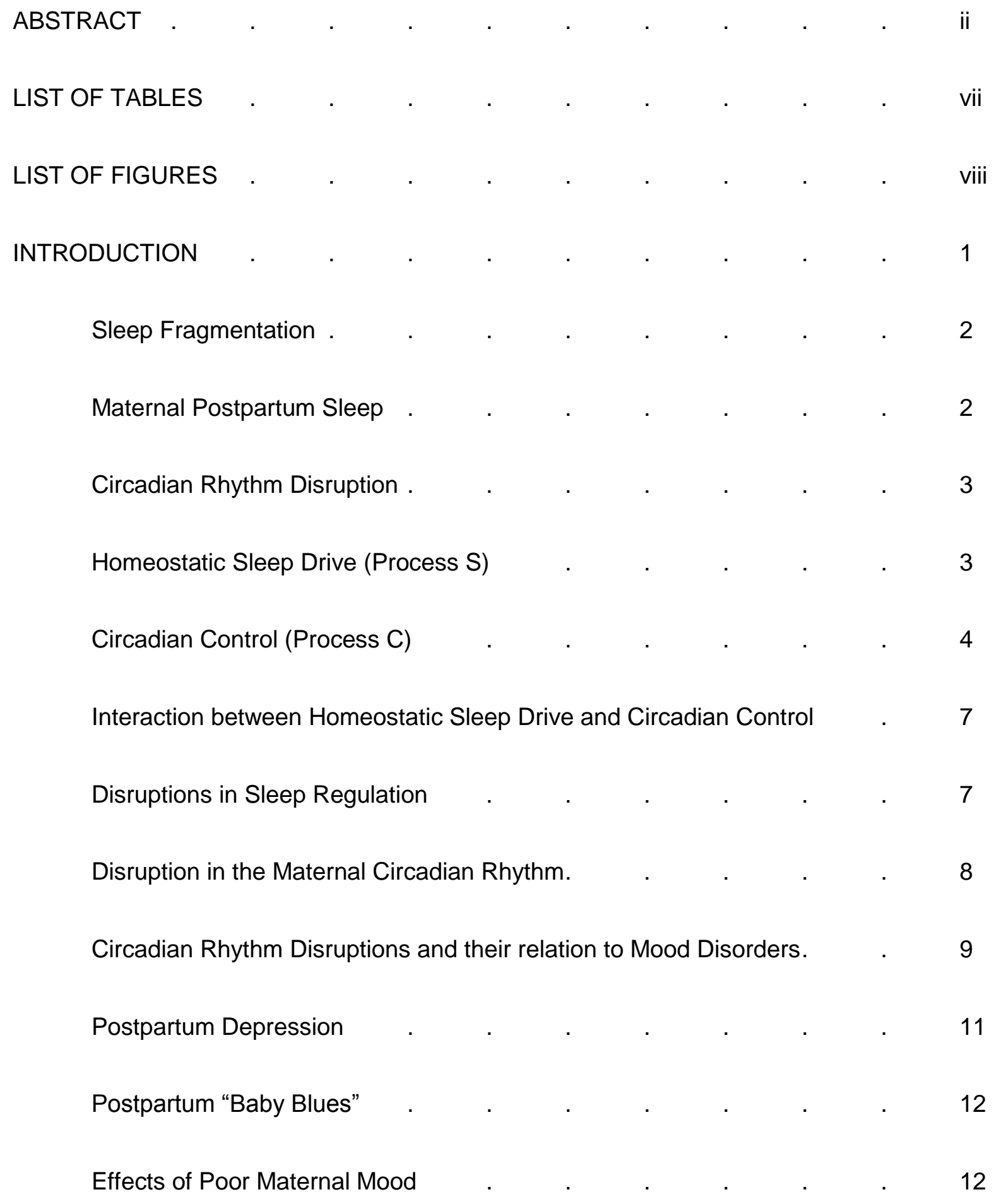




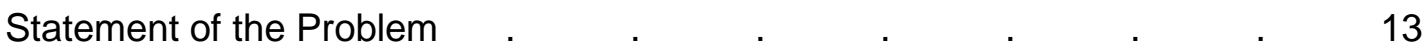

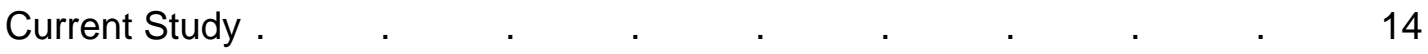

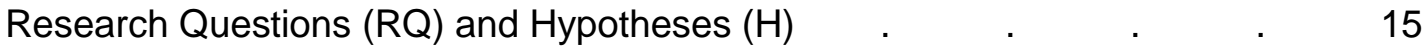

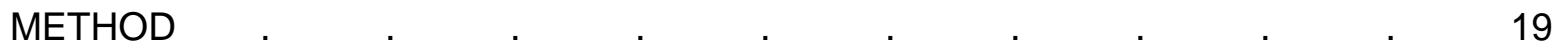

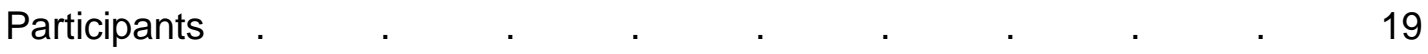

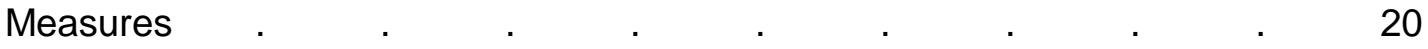

Actigraphy . $\quad . \quad$. $\quad . \quad$. $\quad . \quad$. $\quad . \quad 20$

$\begin{array}{lllllll}\text { Personal Digital Assistant (PDA) } \quad . \quad & \text {. } & \text {. } & \text {. } & \text {. } & 21\end{array}$

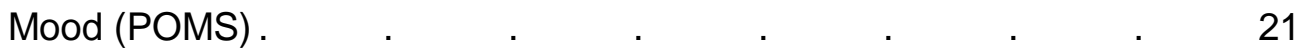

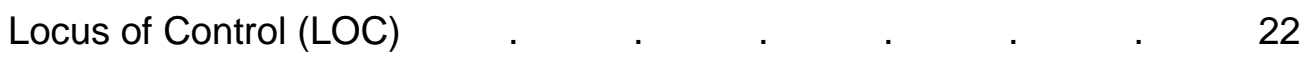

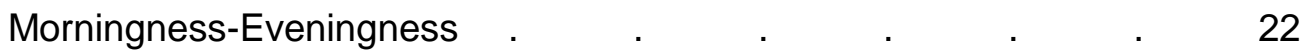

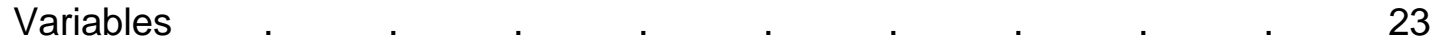

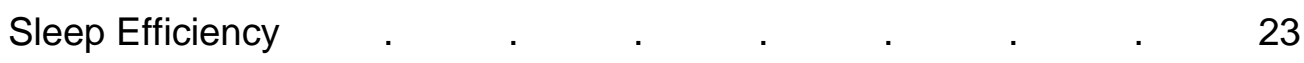

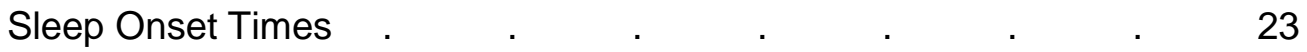

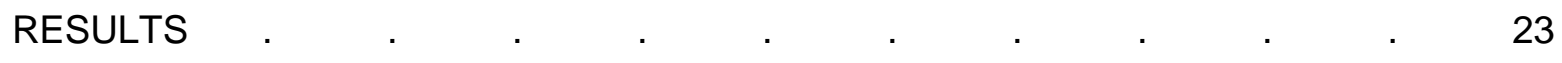

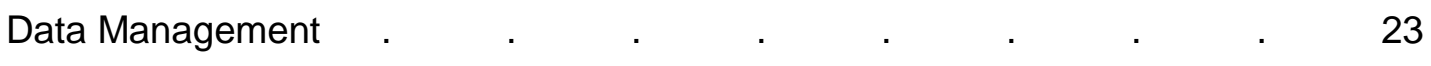

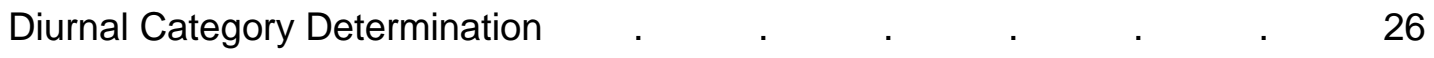

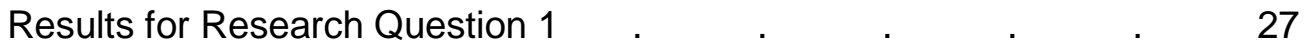


$\begin{array}{lllllllll}\text { Results for Research Question } 2 & \text {. } & \text {. } & \text {. } & \text {. } & & 28\end{array}$

Results for Research Questions 3 and 4 . $\quad . \quad$. 30

Results for Research Question $5 \quad$. $\quad$. $\quad$. $\quad$. $\quad$. 33

Results for Research Question $6 \quad$. $\quad$. $\quad$. $\quad$. $\quad$. $\quad 33$

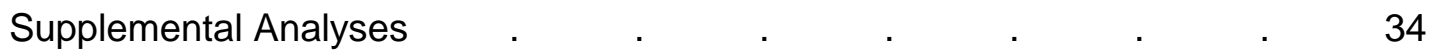

Beck Anxiety Inventory and Perceived Stress Scale. $\quad . \quad$. 36

Beck Anxiety Inventory (BAI) . $\quad$. $\quad . \quad$. $\quad . \quad$. $\quad 37$

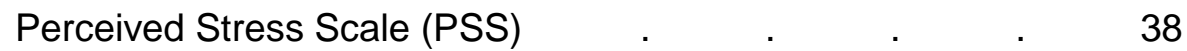

Morningness-Eveningness Scores . $\quad . \quad$. $\quad$. $\quad$. 40

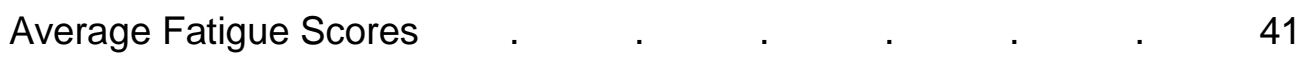

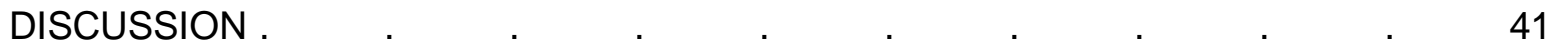

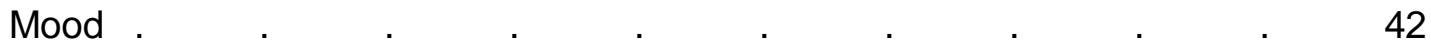

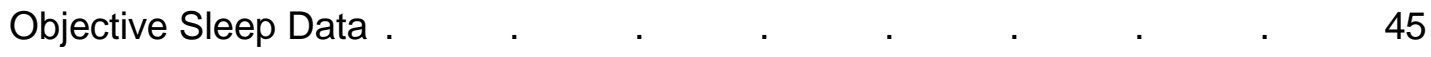

Predictors of Diurnal Rhythmicity Category $\quad . \quad$. $\quad . \quad$. $\quad . \quad$. $\quad 46$

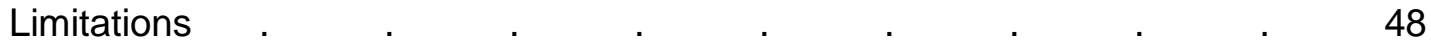

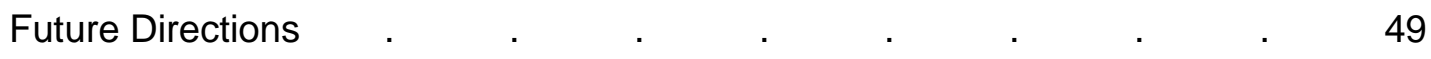

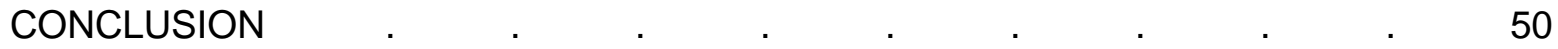

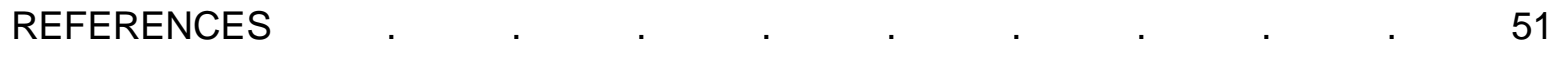


APPENDIX A . $\quad . \quad$. $\quad . \quad . \quad . \quad . \quad . \quad . \quad . \quad . \quad . \quad . \quad 61$ 


\section{LIST OF TABLES}

1. Demographic Characteristics of the total sample $\quad . \quad$. $\quad 25$

2. Descriptive statistics of number of women in each group for analyses used in the study

3. Descriptive statistics of variables in the regression model at postpartum week two

4. Correlations of all variables used in the study . . . . . $\quad 31$

5. Results for hypotheses from research questions 3 \& 4: Stepwise binary logistic regression with independent variables years of education, income, age, morningness-eveningness scores, and locus of control

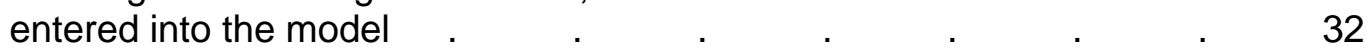

6. Descriptive statistics of variables in the regression model $\quad . \quad$. $\quad 39$

7. Stepwise binary logistic regression with independent variables years of education, income, age, morningness-eveningness scores, and locus of control entered into the model . . . . . . . 


\section{LIST OF FIGURES}

1. Diurnal rhythmicity at postpartum week 2 (a.) and week 12 (b.) and corresponding average POMS

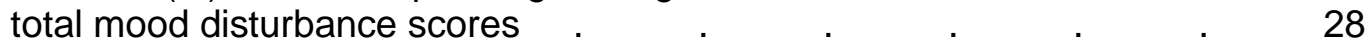

2. Diurnal rhythmicity category at each postpartum week and corresponding average POMS

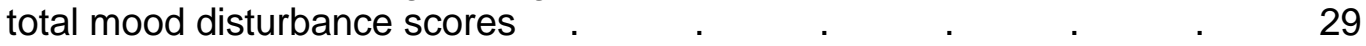

3. Diurnal rhythmicity at postpartum week 2 (a) and 12 (b) in relation to sleep efficiency $\quad . \quad$. $\quad . \quad$. $\quad . \quad$. 33

4. Average variation in sleep onset time during week 2 (a) and week 12 (b) between women with and without a diurnal rhythm . . .

5. Diurnal rhythmicity at postpartum week 12 and corresponding average POMS subscale scores.

6. Diurnal rhythmicity at postpartum week 2 (a) and week 12 (b) and corresponding average BAl scores

7. Diurnal rhythmicity at postpartum week 2 (a.) and week 12 (b.) and corresponding average PSS scores . . . 38

8. Diurnal rhythmicity category at each postpartum week and corresponding average Morningness-Eveningness scores. 


\section{Variances in Diurnal Fatigue Patterns and Mood among Postpartum Women}

\section{Introduction}

The purpose of this study was to further our understanding of the impact sleep disruption has among healthy women during the postpartum period. Specifically, this study primarily examined diurnal circadian rhythm disruptions postpartum in relation to mood. Mood disruptions can occur as a result of circadian rhythm disruptions in healthy individuals. Since women are more susceptible to mood disruptions during the postpartum period, more information is necessary to understand the role postpartum circadian rhythm disruptions may play in mood disturbances. In addition, as an initial step to help identify postpartum women at risk for diurnal rhythm disruptions, predictive factors of an undisrupted diurnal rhythm postpartum were assessed. These factors included demographic variables, morningnesseveningness type, locus of control, and stability of sleep onset times. Findings from this study may help to further describe the relation between circadian rhythms and mood disruption among healthy postpartum women. Not only does this study provide us with a greater understanding of sleep and mood disruptions postpartum, these results may have important clinical implications for screening women at risk for developing postpartum mood disorders.

To provide a context for the current study, a brief background on maternal postpartum sleep fragmentation will be described first. The disruption that sleep fragmentation can cause to maternal circadian rhythms is then explained, followed by a general overview of sleep regulation based on the two-process model of a behavioral homeostatic sleep drive and an endogenous circadian rhythm. The interaction between these components is described to demonstrate that behavioral disruptions to the sleep-wake cycle can impact the circadian rhythm. Finally, the role of circadian rhythm disruptions in mood disturbances among adults and postpartum women is examined. 


\section{Sleep fragmentation}

Sleep deprivation and sleep fragmentation are both types of sleep disturbance that have adverse health consequences. Whereas sleep deprivation is associated with a lack of sufficient sleep quantity, sleep fragmentation affects the quality of sleep. Sleep fragmentation results when sleep cannot be consolidated, and either organic (e.g. sleep apnea) or environmental factors (e.g. ambient noise, caregiving, etc.) result in repeated awakenings from sleep. While the effects of total sleep deprivation have been extensively studied, fewer studies have looked at the effects of sleep fragmentation (Banks \& Dinges, 2007). However, studies have shown that sleep fragmentation causes similar negative effects to sleep deprivation. For instance, sleep disruption among 11 subjects using an audiometer that produced noise via a $1,000 \mathrm{~Hz}$ tone intercom throughout the night for two consecutive nights caused mood and functioning impairment comparable to individuals experiencing total sleep loss of 40-64 hours (Bonnet, 1985). Disturbed sleep also produces impairment in cognitive function, changes in hormone levels similar to sleep deprivation, increases in heart rate and blood pressure, and daytime fatigue (Zaharna \& Guilleminault, 2010). These negative effects of sleep fragmentation are not a result of loss of total sleep time or amount of time spent in specific sleep stages, but are actually the result of a decrease in sleep continuity of the sleep cycle (Bonnet \& Arand, 2003). These adverse health effects are important in the context of the current study because postpartum maternal sleep is characterized by sleep fragmentation.

\section{Maternal postpartum sleep}

Maternal postpartum sleep disruption has been well-documented (Gay, Lee, \& Lee, 2004; Hunter, Rychnovsky, \& Yount, 2009; Montgomery-Downs, Insana, Clegg-Kraynok, \& Mancini, 2010). Specifically, postpartum women obtained more total sleep time than expected. However, their sleep was highly fragmented leading to a decrease in sleep efficiency, meaning they spent significant amounts of time awake at night (Montgomery-Downs et al., 2010). Compared to the last trimester of pregnancy, women in the first postpartum month experience 
less nocturnal sleep, more daytime sleep, and an increased wake after sleep onset (Gay et al., 2005). Matsumoto, Shinkoda, Kang, and Seo (2003) supported the above findings by also reporting a decrease in sleep efficiency and increase in wake after sleep onset. Thus, it is not a loss of total sleep time that is responsible for poor sleep in postpartum women; rather they experience a loss of sleep quality in the form of sleep fragmentation. This can interrupt the natural circadian rhythm of postpartum women.

\section{Circadian Rhythm Disruption}

Sleep fragmentation can cause a disruption in the circadian rhythm, an endogenous regulation of our sleep-wake states. Usually this endogenous circadian rhythm and a homeostatic sleep drive work in harmony to control sleep timing regulation. This model, called the two-process model for sleep regulation, was proposed by Alexander Borbély in 1982 and is the prominent model used today to describe sleep regulation. The model proposes two biological factors that interact to determine sleep propensity throughout the day and night. One process regulates sleep as a function of the time spent in wake and sleep (homeostatic sleep drive). The other regulates sleep timing through an endogenous circadian pacemaker. Borbély coined these factors Process $S$ and Process $C$, respectively (Borbély, 1982). These processes are described in detail below because understanding the interaction of these two processes is integral to fully understanding how the circadian rhythm is impacted by sleep disturbance and thus, to understand the disruption of the circadian rhythm during the postpartum period.

\section{Homeostatic Sleep Drive (Process S)}

The first component of Borbély's model, Process S, is homeostatic sleep pressure. Homeostasis is a coordination of an organism's physiological processes around a relatively constant condition, or optimal set point. Similarly, sleep need varies around an ideal set point by cycling between sleep and wakefulness. There is a quantitative need for sleep that builds during wakefulness and declines during sleep. This buildup in sleep pressure across wake is a homeostatic drive dependent on the amount of time spent awake and the resultant levels of 
neuronal activity during this state. A homeostatic mechanism keeps track of recent neuronal workload, and sustained wakefulness is thought to result in activation of sleep-regulating neurons (Gvilia, 2010).

Since the desire to sleep builds as a function of time spent in wakefulness, sleep deprivation results in profound sleepiness. Increased duration of wakefulness has been associated with increased cognitive performance impairment and subjective sleepiness (Mollicone, Van Dongen, Rogers, Banks, \& Dinges, 2010; Wyatt, Ritz-De Cecco, Czeisler, \& Dijk, 1999). Neurobehavioral tests, such as psychomotor vigilance performance, also worsen as a function of sleep deprivation (Mollicone et al., 2010). The propensity to sleep is also increased during periods of sleep disturbance, such as sleep fragmentation. Animal models have shown increased levels of adenosine, which has been an established biomarker of sleepiness, in rats that have had interrupted sleep (McKenna et al., 2007). Such daytime sleepiness is also evident among postpartum women who experience fragmented sleep (Insana, Stacom, \& MontgomeryDowns, 2011).

\section{Circadian Control (Process C)}

The second component of Borbély's model is Process C, or the endogenous circadian regulator of sleep. It is controlled by a circadian pacemaker that, unlike Process $\mathrm{S}$, is anatomically distinct from the sleep and wake promoting systems (Borbély, 1982); the master circadian pacemaker is located in the hypothalamic suprachiasmatic nucleus. However, oscillators capable of generating regular circadian oscillations have been found in peripheral tissues in Drosophila, zebrafish, and mammals (Cuninkova \& Brown, 2008). Biomarkers commonly used to study circadian rhythmicity include temperature, the hormones melatonin and cortisol, and isolated clock genes and proteins, such as CLOCK, BMAL1, CRY, and PER genes (Dijk \& Archer, 2010; Golombek \& Rosenstein, 2010; Mirick \& Davis, 2008). The "phase response curves" of these biomarkers provide important information regarding their period, phase, and amplitude, all of which can be studied in circadian rhythm disruptions. Circadian 
period is the total amount of time needed to complete one circadian cycle, circadian phase is the time of day when the circadian period peaks or troughs, and circadian amplitude corresponds to the strength of the rhythm, characterized by varying levels of biomarkers (Johnson, 1999; Sharma, 2003). In this study, the major variable was amplitude of the circadian rhythm, measured by self-reported fatigue scores throughout the day.

Variations in circadian phase have been found across individuals, and have led to the establishment of different descriptive chronotypes. Horne and Östberg developed a scale to assess chronotype, or whether someone is a "morning person" or an "evening person" (Horne \& Ostberg, 1976). This circadian typology is assessed based on varying bedtime and wake time tendencies. People with a morning-type category (i.e., "larks") have an earlier bedtime and wake time than people with an evening-type category (i.e., "owls"). Circadian evening temperature peak has been found to be significantly earlier in morning-type individuals (19:32h) than in evening-type individuals (20:40h) (Horne \& Ostberg, 1976). The Morningness-Eveningness questionnaire was used in the current study to categorize women into morning-type or eveningtype when looking for predictors of circadian rhythm disruption.

Behavioral evidence for circadian involvement in sleep timing regulation is found in experimental subjects living in darkness, completely absent of environmental timing cues (i.e. light, regular meal schedules, etc.). These conditions produce a free-running rhythm in which the sleep-wake cycle becomes desynchronized from the 24-hour day. When subjects were placed in environments absent of time cues, they went to bed progressively later each night, indicating that the free-running rhythm is actually longer than 24 hours. Early studies found a free-running rhythm of about 25 hours (Aschoff, 1965), but a more recent study with more stringent environmental controls found this period to be about 24.18 hours (Czeisler et al., 1999). These studies provide evidence that the free-running circadian period of the pacemaker is longer than 24 hours, indicating the circadian clock must be reset on a daily basis by photic and non-photic time cues, referred to as "zeitgebers" (Schulz \& Steimer, 2009). 
The light-dark cycle is the most powerful zeitgeber, and light inputs to the retina help entrain the suprachiasmatic nucleus in diurnal mammals during the day through the retinohypothalamic tract. Melanopsin is the photopigment responsible for light entrainment and is located in the retinal ganglion cells (Moore, 2007; Saper, Scammell, \& Lu, 2005). Absence of light during the nocturnal dark period causes the pineal gland to release melatonin. Melatonin concentrations rise around bedtime and peak at about 3:00 AM, then decline to minute levels by the morning. Melatonin thus acts as a circadian pacemaker that synchronizes the internal environment with the external light-dark cycle (Mirick \& Davis, 2008). The timing of light can have circadian rhythm altering effects. Exposure to light, especially blue light with a 470nm wavelength, suppresses the release of melatonin. Therefore, exposure to light in the early part of the night delays the circadian rhythm, causing later bed and rise times, while light exposure in the early morning advances this rhythm, causing earlier bed and rise time (Czeisler et al., 1986; Sato, Sakaguchi, \& Morita, 2005). However, this also suggests that exposure to light during the nocturnal hours, as often happens to postpartum women during infant caregiving, could disrupt this circadian pacemaker.

Other, non-photic, zeitgebers also play a role in circadian rhythm entrainment. Caloric restriction and scheduled feeding times can reset the biological clock in rats and mice independent of photic cues (Castillo, Hochstetler, Tavernier, Greene, \& Bult-Ito, 2004; Mendoza, Drevet, Pévet, \&Challet, 2008). Support for a role of appropriately timed exercise for shifting and entrainment of the human circadian clock has also been found (Mistlberger \& Skene, 2005). In addition, the behavioral component of the sleep-wake cycle has been shown to modulate endogenous circadian rhythm timing, further synthesizing Borbély's processes S and C (Dijk \& von Schantz, 2005; Franken \& Dijk, 2009). If the current study finds benefits of having an established circadian rhythm postpartum, these zeitgeber techniques could be used for possible interventions. 


\section{Interaction between Homeostatic Sleep Drive and Circadian Control}

The two-process model describes sleep propensity as the interaction between Process S and Process C (Borbély, 1982), and research has supported this model. As sleep drive (Process S) accumulates across the waking day, an increasing circadian wake drive (Process C) compensates for the buildup of sleepiness and results in a relatively steady level of wakefulness across the day. As the need for sleep dissipates quickly in the first few hours of sleep, an increase in circadian sleep drive (Process C) in the second half of the night allows sleep to continue regardless of the corresponding low homeostatic sleep drive (Process S) (Dijk \& von Schantz, 2005).

This interaction suggests there is a behavioral component to entrainment of the circadian rhythm, since sleep propensity is dependent on both behavioral and endogenous processes. Self-reported sleepiness and fatigue are sensitive to sleep deprivation, as well as circadian oscillations (Babkoff, Caspy, \& Mikulincer, 1991; Mistlberger \& Skene, 2005). The interaction of these processes is further supported by the role of human sleep-wake schedules on circadian rhythms (Cajochen, Jewett, \& Dijk, 2003). Under dim light conditions (between 5 13 lux), periods of sleep deprivation were associated with a delay in melatonin onset on subsequent nights, indicating circadian rhythmicity can be behaviorally manipulated. This is especially relevant to the current study because if circadian rhythmicity is influenced by behavior, then awakening women throughout the night for infant caregiving may disrupt their circadian rhythm. This relation between postpartum women and sleep fragmentation has been understudied.

\section{Disruptions in Sleep Regulation}

Normally there is harmony between Process S and Process $\mathrm{C}$, and the sleep-wake cycle is regulated such that adult humans sleep at night and are awake during the daytime. However, certain developmental circumstances, disorders, or behavioral choices can interrupt this regulation, causing misalignment of the circadian system and desired behavioral sleep-wake 
cycle. This misalignment prevents the individual from sleeping during the desired sleep time. Jet lag and shift work disorder are two examples of times when our circadian rhythm and desired sleep-wake cycle become disrupted. Because light is such a powerful entrainment mechanism or zeitgeber - for the circadian rhythm, treatment for shift work disorder focuses on the use of extremely bright light during night shift work and subsequent avoidance of light during the daytime (Zisapel, 2001). Unlike circadian rhythm sleep disorders, jet lag's effect is only temporary, persisting until the circadian rhythm successfully aligns to the light-dark cycle of the new time zone (Auger \& Morgenthaler, 2009).

In addition, shift-workers with an internal locus of control showed better sleep quality, lower fatigue levels, and increased alertness (E. Samaha, Lal, N. Samaha, \& Wyndham, 2005; Smith \& Iskra-Golec, 2003). Locus of control assessments determine the extent to which individuals think they have control over aspects of their life (internal locus of control) versus the belief that things are outside of their control (external locus of control) (Rotter, 1966). This locus of control assessment was used in the current study to test whether perception of control over various aspects of one's life is related to postpartum circadian rhythm disruption.

\section{Disruption in the Maternal Circadian Rhythm}

A decrease in circadian amplitude occurs in women during the postpartum period (Matsumoto et al., 2003). This disruption of maternal sleep postpartum arises because infants are not born with a stable circadian sleep-wake rhythm; instead, circadian rhythms are entrained over a period of time by maternal and environmental cues. According to Kleitman and Engelmann (1953), infants establish this sleep-wake rhythm between the $12^{\text {th }}$ and $14^{\text {th }}$ week of life. A more recent review of sleep development during the first months of life confirmed that most infants develop a normal sleep-wake rhythm within three months after birth (de Weerd \& van den Bossche, 2003).

Interestingly, a noticeable, albeit lower, circadian amplitude in infants has been discovered as early as 3-14 days after birth. However, a stable sleep-wake cycle was not 
observed until about four months after birth, when the infants averaged about 9 hours of sleep per night (Wulff \& Siegmund, 2000). Another study found beginnings of a circadian sleep-wake rhythm in infants during the third week after birth with the amplitude increasing from week 6 to week 12 (Nishihara et al., 2002). The implications of the development of a stable circadian rhythm in infants are important for parents as it influences the integrity of their own sleep. Strong correlations between maternal nocturnal awakenings and infant movements indicative of wake have been found (Wulff \& Siegmund, 2000; Nishihara et al., 2002). Mothers also show lower circadian amplitude after childbirth, indicating a less stable rhythm (Nishihara et al., 2002; Thomas \& Burr, 2006; Wulff \& Siegmund, 2000). However, a lower amplitude was not detected in fathers (Wulff \& Siegmund, 2000). Additionally, the fathers reported that their nocturnal activity resulted from indirect disturbances, such as their partner's noise while attending to the infant. This finding shows a correlation between attending to the infant during the nighttime and a disruption of the circadian rhythm that is not found when nocturnal awakenings are based on noise alone.

\section{Circadian Rhythm Disruptions and their relation to Mood Disorders}

The consequences of circadian rhythm disruption outside of the postpartum population have been well examined in mood disorders such as depression and bipolar disorder. Both Mendlewicz's (2009) and Kennaway's (2010) reviews found relations between several circadian clock genes and mood disorders. Polymorphisms of circadian clock genes CLOCK, BMAL1, and PER3 have been associated with an increased risk for depression (Mendlewicz, 2009). A relation also exists between circadian rhythm disorders and symptoms of depression (Shirayama et al., 2003). Additional support is provided by Monteleone and Maj's review (2008) which evidences an association between a disruption of the normal circadian rhythm and mood disorders such as depression and seasonal affective disorder.

Depressive symptoms occur in diurnal patterns, with generally worse moods occurring in the morning among individuals with clinical depression (Rusting \& Larsen, 1998). There is also 
some evidence of an evening-worse pattern of mood among mildly depressed individuals (Rusting \& Larsen, 1998). These diurnal patterns lend support for a circadian-based component of depression. Additionally, over half of depressed patients have been found to respond to total sleep deprivation with a remarkable improvement in mood and alleviation of depressed symptoms (Reimann et al., 1999; Wirz-Justice \& Van den Hoofdakker, 1999). However, this effect is acute; most of these patients relapse to a depressed state following the next night of sleep. Reimann et al. (1999) examined the effect of experimental delaying or advancing bedtime by a few hours following a night of total sleep deprivation among depressed patients. These delays and advances in sleep time were continually shifted one hour backward and one hour forward (respectively) each day until the initial sleep phase was attained (21:00-06:00), as is done in chronotherapy protocols. This advanced sleep phase shift was effective in preventing the relapse of depressive symptoms among $75 \%$ of the patients who benefitted from the single night of total sleep deprivation. The delayed sleep phase shift was effective in just $40 \%$ of the patients. While the mechanism behind the differences between these phase shifts is unclear, it is clear that circadian rhythms play a unique role in treatment of depression.

Arguably the most convincing evidence of a link between circadian rhythm disruption and depression is seasonal affective disorder. Seasonal affective disorder is characterized by recurrent episodes of depression in the fall and winter that remit in the spring and summer. While vitamin D is hypothesized to have a central role in seasonal affective disorder, it has yet to be conclusively confirmed, and the exact etiology of this disorder remains unknown (Humble, 2010). Strong evidence, including the effectiveness of light therapy as a treatment, supports a circadian role (Humble, 2010; Sohn \& Lam, 2005; Terman, Terman, Lo, \& Cooper, 2001). The success of light therapy as a treatment suggests that the seasonal changes of depressive symptoms may be a result of failure to synchronize the circadian rhythm with the shift in day length that occurs with the changing seasons. This becomes particularly important for the 
current study because we also know there is a disruption in mood among women during the postpartum period.

\section{Postpartum Depression}

Between $10-15 \%$ of childbearing women are diagnosed with postpartum depression (Ross, Murray, \& Steiner, 2005). Adverse outcomes of postpartum depression include disruption in the marriage, increased neglect in child caregiving, a poorer mother-child relationship, delayed child development, and increased risk for maternal suicide or infanticide (Field, 2010; McCoy, 2011; Righetti-Veltema, Conne-Perreard, Bousquet, \& Manzano, 2002). McCoy (2011) reviewed the etiology of postpartum depression, revealing five studies that support the idea that sleep disturbance can be a cause as opposed to an effect of postpartum depression. One of these studies included 465 women who did not have depression at one month postpartum; difficulty falling asleep at one month postpartum was significantly related to the development of depression at four months postpartum (Chaudron et al., 2001).

What we do not fully understand is the role circadian rhythm disruption plays in postpartum mood disruption. Limited research has shown a relation between circadian rhythm disruptions and postpartum depression. A study of 24 women in their first postpartum year (13 with major depression and 11 controls) and found an increase in nocturnal plasma melatonin, especially between the hours of 06:30 and 09:30, in the women with major depression compared to the healthy controls. Declining levels of gonadal hormones in healthy postpartum women would decrease melatonin, but this decrease in estradiol and progesterone did not occur in women with major depression. Women with major depression may be less sensitive to the effects of gonadal hormones on melatonin levels (Parry et al., 2008). More recently, a small study of participants with postpartum depression who wore glasses that block blue wavelength light when caregiving at night were found to recover from depression faster than controls who wore placebo glasses without the ability to block blue light (Bennett, Alpert, Kubulins, \& Hansler, 
2009). Since circadian rhythms are regulated by light (especially blue light), this study supports a connection between circadian rhythm disruption and postpartum depression.

\section{Postpartum "Baby Blues"}

Much more common than postpartum depression is a less severe form of mood disturbance during the early postpartum period that has been reported to effect between 30 $75 \%$ of new mothers (Seyfried \& Marcus, 2003). This mood disruption, known as the "baby blues", has an onset between the third and fourth day postpartum, with a peak in negative mood at day five, and a resolution of mood disturbance typically by day 10 (Ross et al, 2005; Seyfried \& Marcus, 2003). Despite the high prevalence, there is no well-established criterion for diagnosing the postpartum blues (Seyfried \& Marcus, 2003). There is also limited evidence to show sleep loss in the early postpartum period is related to development of the postpartum blues (Ross et al, 2005). It was expected that many women in the current study would show negative mood, as a result of the baby blues, in the immediate postpartum period that would be independent of sleep variables, including the effects of a circadian rhythm disruption.

\section{Effects of Poor Maternal Mood}

A relation between poor maternal mood and poorer infant temperament and infant cognitive development has been found (Galler \& Harrison, 2000; Galler, Harrison, Ramsey, Butler, \& Forde, 2004). These findings are particularly relevant to the current study because, as in the current study, a continuous measure of mood was used among women to study these variables, as opposed to categorizing women as depressed or not depressed. A significant negative correlation was found between depressive mood and infant cognitive development at 3 months postpartum (Galler \& Harrison, 2000). Infant difficulty ratings at 6 months postpartum were also found to be negatively associated with maternal mood at 7 weeks postpartum, after accounting for covariates (Galler et al., 2004). 
We know that sleep fragmentation is related to mood disturbances, and poor mood is related to adverse effects on both the mother and infant. In order to effectively intervene, we must understand exactly how and why this sleep fragmentation is related to disturbances in mood. Sleep fragmentation can cause a disruption in the circadian rhythm, so it is vital that we understand this piece of the story to enhance treatment approaches for postpartum women. The current study is a first step in solving this puzzle by relating circadian rhythm disruption to mood disturbances in healthy postpartum women.

\section{Statement of the Problem}

Despite evidence for early development of a circadian rhythm in infants, due to frequent feeding requirements, it is not until they are approximately 3 months old that most infants develop the ability to sleep "through the night" (Kleitman \& Engelmann, 1953; de Weerd \& van den Bossche, 2003). As a result, women may respond to their infant frequently throughout the night, causing a disruption in their own sleep, and consequently to their circadian amplitude (Matsumoto et al., 2003).

Circadian rhythm disruptions are related to mood, with circadian disorders and circadian rhythm dysfunctions common among depression patients (Mendlewicz, 2009). Also, some women experience a disruption in mood during the postpartum period. Ross et al. (2005) found that $10-15 \%$ of women are clinically diagnosed with postpartum depression. Further, anywhere between $30-75 \%$ of women report mood disruption within the first week postpartum in the form of the "baby blues" (Seyfried \& Marcus, 2003). Associations between disruption of circadian rhythm and postpartum depression have been found (Bennett et al., 2009; Parry et al., 2008). Finally, poorer mood postpartum is correlated with poorer infant cognitive development and more difficult infant behavior (Galler \& Harrison, 2000; Galler et al., 2004). Thus, circadian 
rhythm disruptions may be related to not only the mother's mood but the infant's development as well.

However, these studies have focused on the relation between circadian rhythms and the clinical diagnosis of postpartum depression; we should also be concerned with mood in postpartum women without a diagnosis of postpartum depression (Galler \& Harrison, 2000; Galler et al., 2004). There is a lack of knowledge pertaining to circadian rhythm disruption as it relates to mood in otherwise healthy postpartum women. The connection between mood and presence or absence of a diurnal rhythm amplitude that is strong enough to be detected through women's self-reported fatigue levels at different times in the postpartum period has not been examined among healthy subjects. Nor have any factors that predict diurnal rhythm among healthy postpartum women been studied. Studying rhythm disruption among postpartum women has implications beyond discovering more about the normal postpartum period. It might be used as a tool to screen women at risk of developing disruptions in mood during the postpartum period, as well as providing more general information about relations between mood and sleep fragmentation.

\section{Current Study}

The current study goal was to fill in the gaps of our knowledge by addressing diurnal rhythm disruption among healthy postpartum women. Women were categorized based on whether the amplitude of their daytime (diurnal) rhythm was strong enough to be detected. This rhythm was measured through a compilation of self-reported fatigue level over a one week time period. When fatigue scores were plotted with respect to the time of day they were filled out, significant linear, quadratic, or cubic trends were categorized as having a rhythm, whereas those with randomly distributed fatigue scores were categorized as not having a rhythm. The presence or absence of this rhythm was analyzed in relation to mood disruption. Additionally, 
changes in presence or absence of rhythmicity at the beginning and end of the first 3 postpartum months and associated changes in mood, sleep efficiency, and variations in sleep onset time were examined.

The current study also examined factors that help explain postpartum women's presence or absence of a rhythm. Locus of control, morningness-eveningness type, and demographic characteristics, such as age and income, were all examined as possible predictors of rhythmicity. Identification of predictors of this rhythm might help with early interventions of techniques targeted at maintaining a rhythm in postpartum women.

\section{Research Questions (RQ) and Hypotheses (H)}

RQ1: What are the self-reported mood score differences between circadian category (women with or without a rhythm) at the early postpartum period (postpartum week 2) compared to the later postpartum period (postpartum week 12)?

$\mathrm{H1}$ : Women with diurnal rhythms will have better mood scores than mothers without diurnal rhythms at week 12 , but there will be no statistically significant difference between circadian categories and mood scores at week 2.

This hypothesis is based on preliminary findings suggesting this possible interaction (McBean \& Montgomery-Downs, 2010). Other support for this hypothesis centers around the "baby blues" phenomenon that affects between $30-75 \%$ of women in the first couple weeks postpartum (Seyfried \& Marcus, 2003). Since this mood disruption is a relatively common short term occurrence immediately after giving birth, it is unlikely to be influenced by circadian rhythm disruption.

RQ2: How does stability or change between circadian categories from the early postpartum period (postpartum week 2) to later (postpartum week 12) relate to self-reported mood scores? 
$\mathrm{H} 1$ : Women who have a diurnal rhythm at both week 2 and week 12 will report an improvement in mood score from week 2 to week 12.

$\mathrm{H}$ 2: Women who have a diurnal rhythm at week 2 but not at week 12 will show a worsening in mood scores from week 2 to week 12.

H3: Women who do not have a diurnal rhythm at week 2 but have one at week 12 will show an improvement in mood scores from week 2 to week 12 .

H4: Women who do not have a diurnal rhythm at either week 2 or week 12 will show a worsening in mood scores from week 2 to week 12 .

These hypotheses are all based on the notion that presence of a diurnal rhythm will be related to better mood scores among healthy women. Mood disorders are often associated with circadian rhythm dysfunction (Kennaway, 2010; Mendlewicz, 2009). Parry et al. (2008) have shown that high melatonin levels have been associated with postpartum depression. These hypotheses support the notion that when a rhythm is present, an improvement in mood will be found.

RQ3: Are there differences in morningness-eveningness type traits and locus of control between circadian categories in the initial postpartum period (postpartum week 2)?

$\mathrm{H} 1$ : Women with a diurnal rhythm at postpartum week 2 will be more morning-type.

This hypothesis is supported by Taillard, Philip, and Bioulac (1999) who found that eveningtypes were significantly more likely to vary their bed and rise times by over two hours than morning-types or neither-types, suggesting morning-types may be more likely to display a diurnal rhythm.

$\mathrm{H} 2$ : Women with a diurnal rhythm at postpartum week 2 will have higher internal locus of control scores. 
Although no studies have shown a direct relation between rhythmicity and locus of control, an internal locus of control in shift-workers was associated with better sleep quality, lower levels of fatigue, and higher alertness (Samaha et al., 2005; Smith \& Iskra-Golec, 2003). Extending results from these studies, an internal locus of control is hypothesized to be related to presence of a diurnal rhythm in the postpartum period.

RQ4: Are there demographic differences between women in different circadian categories at the initial postpartum period (postpartum week 2)?

H1: Postpartum women with a diurnal rhythm at postpartum week 2 will have higher annual household income.

This hypothesis is based on the notion that low-income families may have an additional financial stressor associated with becoming parents. Yamazaki (2007) showed evidence of a relation between a strong sleep-wake rhythm and higher income levels among postpartum Japanese women in the first 4-5 weeks postpartum. In addition, Tu, Lupien, and Walker (2006) found an association between women with a higher household income and a regular, declining pattern of cortisol levels throughout the day.

H2: Postpartum women with a diurnal rhythm at postpartum week 2 will have more years of education.

It is thought that more highly educated women will have a greater knowledge of what to expect in the postpartum period and may be better able to regulate their child's sleep, and thus have more control over their own. Hale, Berger, LeBourgeois, and Brooks-Gunn (2009) found 3-year old children of mothers with less than a high school education are $30 \%$ less likely to have a regular bedtime and bedtime routine than children of mothers with at least a high school education, suggesting a role for maternal education in development of bedtime routines. However, no evidence could be found to support this in the early postpartum period. 
Additionally, Arber, Bote, and Meadows (2009) found a relation between an increase in sleep problems in adults between the ages of 16 and 74 with low education after adjusting for health variables.

H3: Postpartum women with a diurnal rhythm at postpartum week 2 will be older.

This hypothesis is based on the delayed sleep phase shift that occurs during adolescence. It is not known exactly when this rhythm shifts back to the characteristic adult circadian phase, but it is thought to be between the ages of $18-21$ on average (Roenneberg et al., 2004). If a woman has a child when her circadian rhythm is still in this delayed phase shift, it would likely cause even more disruption of her rhythm than if her rhythm had already developed into its adult phase prior to giving birth. This may be confounded by the increased sleep need in adolescence compared to young adults, and the fact that younger women in this study may still have a larger sleep need than older women (Wolfson \& Carskadon, 1998).

RQ5: How does presence or absence of a diurnal rhythm relate to sleep efficiency as measured by actigraphy (in both postpartum weeks 2 and 12)?

H1: Women who have a diurnal rhythm will have higher sleep efficiency at both postpartum weeks 2 and 12 .

Matsumoto's (2003) longitudinal study of ten postpartum mothers for from the third trimester through the first 15 postpartum weeks found concurrent decreases in sleep efficiency and circadian rhythm amplitude, however, these variables have not been examined in relation to each other during the postpartum period. This study sought to examine if a disruption in circadian rhythmicity is correlated to a decrease in sleep efficiency.

RQ6: How does presence or absence of a diurnal rhythm relate to variance in sleep onset time, as measured through actigraphy, at postpartum weeks 2 and 12? 
H1: Women who have a diurnal rhythm will have a less variable sleep onset time at both postpartum weeks 2 and 12.

Sleep onset times are related to a corresponding decrease in cortisol levels (Balbo, Leproult, \& Van Cauter, 2010). Because cortisol is a biomarker of circadian rhythmicity, a disruption in rhythmicity should be associated with irregular cortisol levels. Since cortisol levels and sleep onset time are coupled together, it should follow that irregular cortisol secretions would be associated with more irregular sleep onset times.

\section{Method}

The current study utilized an existing longitudinal dataset from a larger field study that took place from April 2007 - April 2010, about maternal sleep disturbances during the second through thirteenth postpartum weeks. The larger study aims were to determine whether sleep disruption, consisting of sleep fragmentation and sleep deprivation, was associated with increased functional impairment, and whether sleep fragmentation alone would account for more of the functional impairment than sleep deprivation. Data were collected beginning at the end of the first postpartum week for a total of 12 continuous weeks.

\section{Participants}

Women were recruited during pregnancy using methods designed to include a large range of socioeconomic status and diverse racial/ethnic participants. Recruitment was through community advertisements, obstetric and midwifery clinics, childbirth classes, and offices that administer the Women, Infant, and Children Supplemental Nutrition Program (WIC). Exclusion from participation included a history, current diagnosis, or high risk of major depressive disorder, defined as a score of $>16$ on the 20 -item Center for Epidemiologic Studies Depression Scale (CES-D) (Radloff, 1977). Additional exclusion criteria included premature delivery, pregnancy 
with multiples, infant admission to the neonatal intensive care unit, and/or discharge from hospital after the standard 2 (for vaginal delivery) to 3 (for surgical delivery) days postpartum.

Women who completed the study received compensation at $\$ 4$ a day for the 12 week study period ( $\$ 336$ total). A small toy or book was also provided for the infant at each of the 12 weekly home visits. Women excluded from the study based on high risk for major depressive disorder were referred for evaluation.

\section{Measures}

\section{Actigraphy}

Nonintrusive, continuous sleep state monitoring was recorded using Mini Mitter Actiwatch®-64 (AW64) actigraphs. Motion was read via an accelerometric sensor that provides mathematical calculations using digital integration. Data from movement and movement intensity were downloaded and calculations were made via a computerized reader and software. Default (medium) sensitivity setting was used to detect sleep and wake periods with the highest epoch resolution (15 seconds). The device looks like a wrist watch and was worn continuously on a strap around the woman's nondominant wrist. Its weight is $17.5 \mathrm{~g}$ and measures $28 \times 27 \times 10 \mathrm{~mm}$. The use of the AW64 in detection of adult sleep-wake patterns has been validated (Benson et. al., 2004; Edinger, Means, Stechuchak, \& Olsen, 2004). Sleep onset and offset times were participant identified in real time on a personal digital assistant (PDA). Retrospective sleep and wake times were recorded and labeled as such when participants did not record these in real time. Reported sleep onset and offset times were synched with actigraphy movement data to determined sleep periods. Sleep onset was identified as the first 2 minute period of immobility proceeding reported sleep times. Sleep offset was determined as the last 2 minute period of immobility preceding participant reported wake time. 


\section{Personal Digital Assistant (PDA)}

A Palm Zire 72 personal digital assistant (PDA) with software customized for this study (Bruner Consulting, Inc.) was used by participants to record sleep times and complete surveys. Included in this software was a visual analog of fatigue scale assessment that was selfadministered 3-4 times per day (concurrent with diurnal infant feedings). Participants were asked, "How tired/fatigued do you feel RIGHT NOW?" This fatigue rating was on a 0-100 scale with "0" representing "not at all tired" and "100" representing "very tired". This assessment was derived from Monk's (1989) Global Vigor and Affect visual analog scale, which has been validated in studies of depression as it relates to diurnal variation and jet lag (Monk, 1989). It has been further validated in studies of circadian rhythmicity (Monk et al., 1997). The fatigue data from this visual analog scale was used to assess each participant's presence or absence of a circadian rhythm at postpartum weeks 2 and 12 in the current study. All data from the visual analog of fatigue scores and time of day at which they were completed over a period of one week was combined onto one scatterplot for each participant. This resulted in two fatigue score data scatterplots for each participant, one for each of weeks 2 and 12. Each participant's data was analyzed using regression statistics for a significant linear, quadratic, or cubic trend $(p<0.05)$. Presence of any of these three trends was categorized as the presence of circadian rhythmicity. Lack of statistical significance was categorized as absence (or disruption) of circadian rhythmicity.

\section{Mood (POMS)}

The Profile of Mood States (POMS) was administered at the end of even-numbered postpartum weeks. The POMS consists of 65 adjectives rated by subjects using a 5-point Likert scale. Six subscales have been derived from the POMS: tension-anxiety, depression-dejection, anger-hostility, vigor-activity, fatigue-inertia, and confusion-bewilderment. A high total POMS 
score represents worse mood. Internal consistencies of the POMS when administered to adults 17-60 years old ranged from 0.84 (confusion-bewilderment scale) to 0.95 (depression-dejection scale) (McNair, Lorr, \& Droppleman, 1992). Its use with postpartum women has been seen in assessments of psychological status (Fisher, Feekery, \& Rowe-Murray, 2002; Hayes, Muller, \& Bradley, 2001), breastfeeding (Groer, Davis, \& Steele, 2004) and exercise (Koltyn \& Schultes, 1997). In the current study, total general mood disturbance scores were used. The subscales were examined in supplemental analyses.

\section{Locus of Control (LOC) (see Appendix A)}

Locus of control assessments were collected during the initial home visit. The assessment is a standardized 29 -item questionnaire consisting of 23 forced choice items (6 questions do not affect the score). The questionnaire assesses the extent to which subjects believe outcomes are contingent on internal sources of control versus external sources of control. Higher scores indicate more external locus of control. This questionnaire has been validated in over 20 studies (reviewed in Rotter, 1966).

\section{Morningness-Eveningness (see Appendix A)}

Morningness-Eveningness assessments were collected during the initial home visit. The assessment consists of 9 questions related to daily sleep-wake habits and time of day preference for certain activities and is adapted from Östberg and Horne's original scale. High scores indicate morning-types, while low scores indicate evening-types. The questionnaire has been validated, and significant correlations between evening temperature peak time and Morningness-Eveningness (-0.51), as well as bed time and rise time and MorningnessEveningness (-0.67, -0.79), have been found (Horne \& Östberg, 1976). 


\section{Variables}

\section{Sleep Efficiency}

The sleep efficiency variable used in this study was calculated automatically by the actigraphy software, and was representative of the percentage of 15 second epochs scored as sleep within a designated sleep period. Sleep efficiency was calculated as a percent by dividing the periods scored as sleep by the total period designated as sleep.

\section{Sleep Onset Times}

Variance in sleep onset times for each participant at each of postpartum weeks 2 and 12 was calculated in order to address research question \#6 concerning how presence or absence of a diurnal rhythm relates to variance in sleep onset time. Sleep onset time (from objective actigraphy data) was subtracted from noon for each day in the week, and then the standard deviation of the sleep onset values for the respective week was calculated in minutes. This standard deviation value in minutes was used to represent the variance in sleep onset time.

\section{Results}

\section{Data Management}

Data were checked for missing values prior to conducting analyses. There were originally 71 participants present in the dataset, but missing data were present throughout the dataset from various participants due to equipment malfunction, lack of participant adherence, and participant dropout.

At postpartum weeks 2 and $12,7.0 \%$ and $11.3 \%$ of women were missing fatigue data respectively, and so could not be classified into rhythmicity groups. One of these women at week 12 had only one fatigue data point and was thus excluded. The number of data points for each participant ranged from 7 to 44 for week 2 and from 4 to 33 for week 12 . Number of fatigue 
data points at each of weeks 2 and 12 were normally distributed, and no outliers were present. One-way ANOVAs were used to test for significant differences between diurnal rhythmicity category and number of fatigue points. Women categorized as having a diurnal rhythm had significantly more fatigue reports at both weeks $2(F(65)=14.45, p<0.001, d=0.98)$ and 12 $(F(62)=9.83, p=0.003, d=0.92)$. To test whether women with fewer data points were less likely to be categorized as having a rhythm because they may not have had sufficient data points to allow detection of a significant trend, outliers were evaluated. There were no outliers, so no clear-cut value of data points at which women should be excluded could be established. Consequently, women were removed from the dataset one at a time beginning with those with the fewest fatigue data points until the relation between rhythmicity category and number of fatigue points was no longer significant. At weeks 2 and 12, removal of 28 and 37 participants respectively was necessary, reducing the sample size from $n=66$ to $n=38$ (number of fatigue data points ranged from 19-44) and from $n=63$ to $n=26$ (number of fatigue data points ranged from 17-33) before the relation was no longer significant. Removal of these women reduced the sample sizes below the power necessary to test the study hypotheses. Thus, no women were removed from the dataset on this basis.

Overall, $9.9 \%$ of POMS data were missing at week 3 , and $11.3 \%$ were missing at week 13. Of the women who had fatigue data, $1.5 \%$ of women at postpartum week 2 were missing over half of their weekly sleep data for analyses of sleep efficiency, total sleep time, and variation in sleep onset time; $17.5 \%$ of women at postpartum week 12 were missing sleep data. Pairwise deletion was used in all cases.

Demographic characteristics of the total sample are provided in Table 1. All 71 women who participated in the study contributed to at least one study analysis, but missing data for different variables of interest lowered the number of participants for various analyses. Specific sample sizes for each analysis are provided in their respective sections. 
Table 1

Demographic characteristics of the total sample.

\begin{tabular}{lcccc}
\hline \multicolumn{1}{c}{ Variable } & $\mathrm{n}$ & Mean & $\begin{array}{c}\text { Standard } \\
\text { Deviation }\end{array}$ & Range \\
\hline Age & 70 & 26.39 & 4.04 & $18.4-35.5$ \\
Income & 58 & 61,000 & 35,000 & $5,000-150,000$ \\
Years of education & 71 & 15.73 & 2.9 & $9-22$ \\
Morningness-Eveningness Score & 71 & 19.27 & 4.86 & $7-29$ \\
Locus of Control & 71 & 10.11 & 3.6 & $2-18$ \\
POMS W3 & 64 & 22.58 & 24.67 & $-11-124$ \\
POMS W13 & 63 & 6.63 & 22.98 & $-32-96$ \\
BAI W2 & 71 & 5.89 & 5.26 & $0-26$ \\
BAI W12 & 63 & 3.32 & 3.58 & $0-14$ \\
PSS W5 & 69 & 12.42 & 5.91 & $0-24$ \\
PSS W13 & 62 & 10.45 & 5.59 & $0-25$ \\
Sleep Efficiency W2 & 65 & 79.42 & 6.00 & $61.17-93.94$ \\
Sleep Efficiency W12 & 51 & 87.05 & 6.15 & $67.12-95.34$ \\
Variation in Sleep Onset W2 & 69 & 56.56 & 26.23 & $13.44-129.05$ \\
Variation in Sleep OnsetW12 & 52 & 50.08 & 22.15 & $14.00-118.28$ \\
\hline
\end{tabular}

SPSS version 18.0 was used to analyze data. For all of the following analyses, a $p<0.05$ was considered statistically significant and Cohen's $d$ was used to calculate effect sizes. Figures are shown with standard error bars.

Continuous variables were checked for skewness and kurtosis. POMS at both weeks 3 and 13 were positively skewed and had a platykurtic shape. However, since the POMS at both weeks were skewed in the same direction with similar values (week 3 skewness $=1.46$; week 13 skewness $=1.28$ ), and were both platykurtic with similar values (week $3=3.86$; week $13=$ 3.02), no transformations on the variables were performed. In addition, the POMS has been extensively validated and used in this population (Fisher et al., 2002; Groer et al., 2004; Hayes 
et al., 2001; Koltyn \& Schultes, 1997). Sleep efficiency at week 12 was negatively skewed (skewness $=-1.38$, and variation in sleep onset at week 2 was positively skewed (skewness = 1.18). Both variables were logarithmically transformed and analyses were run on both the raw and logarithmic transformed variables. However, statistical results did not differ; therefore, results are reported on raw values. Variables inputted into the logistic regression model were also checked for normality, outliers, linearity, and homogeneity of variance. Age, income, years of education, morningness-eveningness scores, and locus of control scores were all normally distributed, and none of these variables had outliers. In addition, homogeneity of covariance matrices between these independent variables was checked using Box's $M$, and the value was not significant, suggesting homogeneity can be assumed. However, linearity was not found throughout pairs of independent variables. Specifically, locus of control score was not linearly related to any other independent variables. Additionally, the largest correlation between independent variables in the regression model was between age and income, $r=0.65, p<0.001$. However, this correlation coefficient is not very high; thus, independence of collinearity can be assumed. Due to these reasons, logistic regression was chosen over discriminant analysis.

\section{Diurnal Category Determination}

Women were categorized into diurnal categories through analysis of fatigue scores. All data from the visual analog of fatigue scores and time of day at which they were completed (between 06:00 and 24:00) over a period of one week were combined onto one scatterplot for each participant. This resulted in two fatigue score data scatterplots for each participant, one for each of weeks 2 and 12. Each participant's data were analyzed using regression statistics for a significant linear, quadratic, or cubic trend. A statistically significant value for any of these trends was categorized at each week as presence of diurnal rhythmicity (Yes); lack of statistical significance was categorized as absence of diurnal rhythmicity (No).

Women were further assigned to one of four categories based on their presence or absence of a rhythm at each of postpartum weeks 2 and 12: significant rhythm at both weeks 
(Yes-Yes), no significant rhythm at either week (No-No), rhythm absent at week 2 but present at week 12 (No-Yes), and rhythm present at week 2 but absent at week 12 (Yes-No). Table 2 outlines the number of women in each group. Chi-square analyses on women changing grouping categories from weeks 2 to 12 were not significant, suggesting there is no relation between rhythmicity category at week 2 and rhythmicity category at week 12 .

Table 2

Descriptive statistics of number of women in each group for analyses used in the study.

\section{Week 2 Rhythmicity Category}

Yes No

Week 12

Yes

25

15

43

Rhythmicity

Category

No

7

9

20

40

26

Note: Values in box do not necessarily add up to values reported in summative columns and rows due to missing data for participants at one week but not the other.

\section{Results for Research Question 1}

Research Question 1: What are the self-reported mood score differences between circadian category (women with or without a rhythm) at the early postpartum period (postpartum week 2) compared to the later postpartum period (postpartum week 12)?

Two separate one-way analyses of variances (ANOVAs) (one at postpartum week 2 and one at week 12) were conducted with diurnal rhythmicity category (either significant rhythm or no significant rhythm) as the independent variable and POMS mood score as the dependent variable. In this analysis participants could switch rhythmicity category from weeks 2 to 12 , necessitating the use of separate analyses as opposed to a repeated measures ANOVA. Results are described in Figure $1 \mathrm{a} \& \mathrm{~b}$. 
(a.)

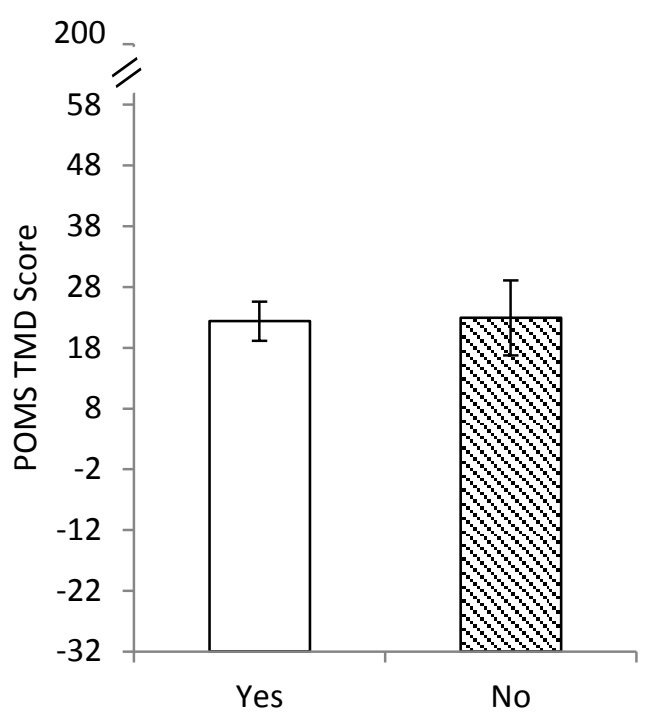

(b.)

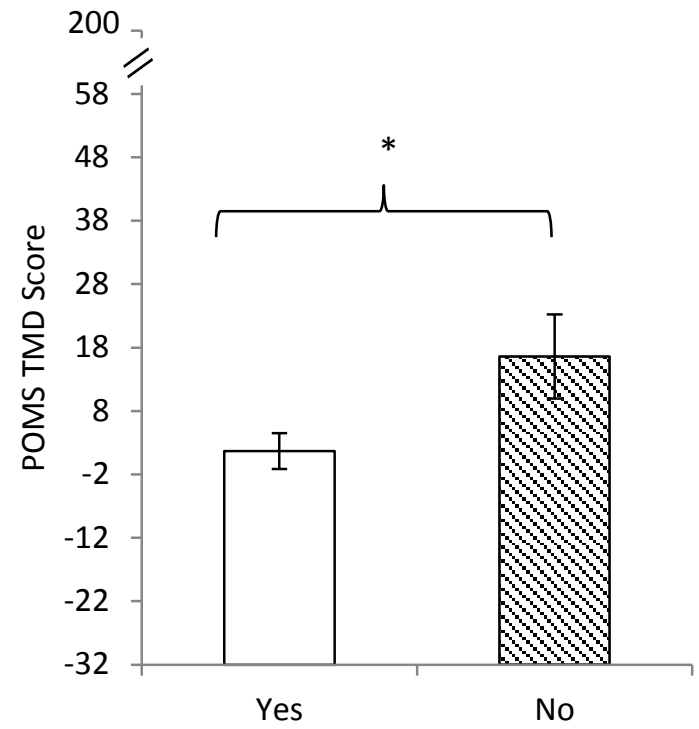

Figure 1 a\&b. Diurnal rhythmicity at postpartum week 2 (a.) and week 12 (b.) and corresponding average POMS total mood disturbance scores. Note: ${ }^{*}=p<0.05$

Hypothesis 1 was supported; women with diurnal rhythms reported significantly better $\operatorname{mood}(M=1.67, S E=2.81)$ than mothers without diurnal rhythms at week $12(M=16.58, S E=$ 6.62), $\mathrm{F}(61)=6.01, p=0.017, d=0.62$. There was no statistically significant difference between diurnal categories and mood scores at week $2, \mathrm{~F}(63)=0.01, p=0.930$.

Supplemental analyses were subsequently conducted on these same variables, but controlling for demographic characteristics. These analyses are described in the supplemental analyses section.

\section{Results for Research Question 2}

Research Question 2: How does stability or change between circadian categories from the early postpartum period (postpartum week 2) to later (postpartum week 12) relate to selfreported mood scores? 
Repeated measures ANOVAs were conducted on the difference in POMS scores (the change score) from postpartum week 2 to week 12 among women with varying diurnal rhythm categories. Results are described in Figure 2.

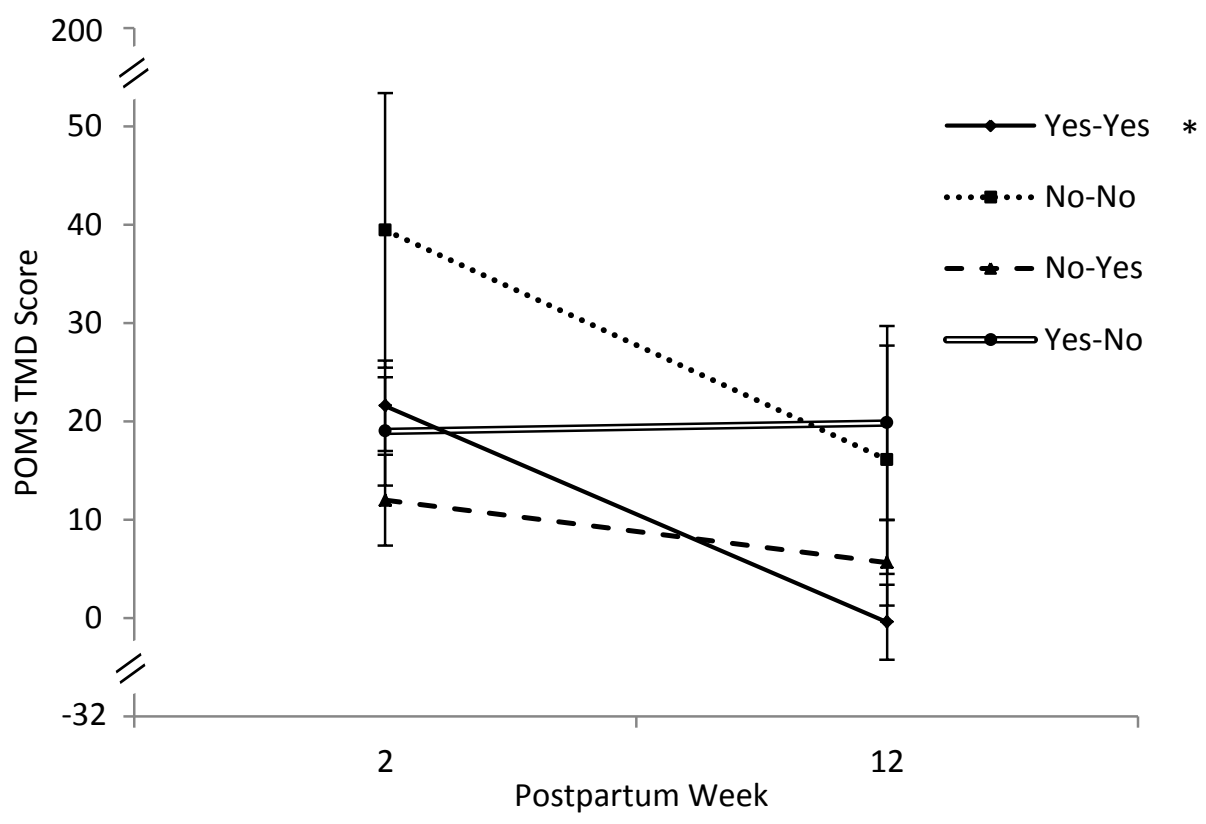

Figure 2. Diurnal rhythmicity category at each postpartum week and corresponding average POMS total mood disturbance scores.

Hypothesis 1 was supported; Women who had a diurnal rhythm at both week 2 and week 12 (Yes-Yes) reported an improvement in mood from week 2 to week 12, F(24) = 20.04, $p<0.001, d=1.05$.

Hypotheses 2, 3, and 4 were not supported. Hypothesis 2: Women with a diurnal rhythm at week 2 but not at week 12 (Yes-No) did not show a worsening in mood from week 2 to week $12, F(6)=0.01, p=0.923$. Hypothesis 3 : Women without a diurnal rhythm at week 2 but with one at week 12 (No-Yes) did not show an improvement in mood from week 2 to week 12, F(14) $=2.92, p=0.110$. Hypothesis $4:$ Women without a diurnal rhythm at either week 2 or week 12 (No-No) did not show a worsening in mood from week 2 to week 12. In fact, the opposite was 
true, they showed an improvement in mood between these two weeks, but this improvement was not significant, $\mathrm{F}(9)=4.90, p=0.058$.

\section{Results for Research Questions 3 and 4:}

Research Question 3: Are there group differences in morningness-eveningness type traits and locus of control between circadian categories in the initial postpartum period (postpartum week 2)?

Research Question 4: Are there demographic differences between women in different circadian categories at the initial postpartum period (postpartum week 2)?

A backward stepwise logistic regression using likelihood ratios was utilized to test hypotheses for both research questions. Descriptive statistics of variables in the regression model are reported (see Table 3) and a correlation matrix was examined (see Table 4).

Table 3

Descriptive statistics of variables in the regression model at postpartum week two

\begin{tabular}{|c|c|c|c|c|}
\hline \multirow[b]{3}{*}{ Variable } & \multicolumn{4}{|c|}{ Diurnal Rhythmicity Category } \\
\hline & \multicolumn{2}{|c|}{ Yes } & \multicolumn{2}{|c|}{ No } \\
\hline & Mean & $\begin{array}{l}\text { Standard } \\
\text { Deviation }\end{array}$ & Mean & $\begin{array}{l}\text { Standard } \\
\text { Deviation }\end{array}$ \\
\hline Income & 67,000 & 36,000 & 51,000 & 31,000 \\
\hline Age & 26.52 & 4.36 & 26.07 & 3.49 \\
\hline Years of Education & 15.79 & 3.12 & 15.88 & 2.49 \\
\hline $\begin{array}{l}\text { Morningness- } \\
\text { Eveningness Score }\end{array}$ & $20.50^{* *}$ & 4.58 & $17.42^{\star *}$ & 4.33 \\
\hline Locus of Control & 10.35 & 3.85 & 10.12 & 3.30 \\
\hline
\end{tabular}

Notes: Variables that were found to be significant in the regression model are labeled as such: ${ }^{* *}=p<0.01$ 
Table 4

Correlations of all variables used in the study

\begin{tabular}{|c|c|c|c|c|c|c|c|c|c|c|c|c|c|c|c|c|c|c|c|c|c|}
\hline Variable & w2 & W12 & $\begin{array}{l}\text { \#Fatigue } \\
\text { Points } \\
\text { W2 }\end{array}$ & $\begin{array}{l}\text { \#Fatigue } \\
\text { Points } \\
\text { W12 }\end{array}$ & $\begin{array}{l}\text { Avg } \\
\text { Fatigu } \\
\text { e W2 }\end{array}$ & $\begin{array}{l}\text { Avg } \\
\text { Fatigu } \\
\text { e W12 }\end{array}$ & Age & Income & $\begin{array}{l}\text { Educat } \\
\text { ion }\end{array}$ & $M-E$ & LOC & $\begin{array}{l}\text { POMS } \\
\text { W3 }\end{array}$ & $\begin{array}{l}\text { BAI } \\
\text { W2 }\end{array}$ & $\begin{array}{l}\text { PSS } \\
\text { W5 }\end{array}$ & $\begin{array}{l}\text { Efficie } \\
\text { ncy } \\
\text { W2 }\end{array}$ & $\begin{array}{l}\text { Sleep } \\
\text { Onset } \\
\text { W2 }\end{array}$ & $\begin{array}{l}\text { POMS } \\
\text { W13 }\end{array}$ & $\begin{array}{l}\text { BAI } \\
\text { W12 }\end{array}$ & $\begin{array}{l}\text { PSS } \\
\text { W13 }\end{array}$ & $\begin{array}{l}\text { Efficie } \\
\text { ncy } \\
\text { W12 }\end{array}$ & $\begin{array}{l}\text { Sleep } \\
\text { Onset } \\
\text { W12 }\end{array}$ \\
\hline $\begin{array}{l}\text { Week } 2 \\
\text { diurnal } \\
\text { category }\end{array}$ & - & 0.18 & $0.43^{* \star *}$ & $0.39^{\star *}$ & 0.17 & 0.09 & 0.06 & 0.23 & -0.02 & $0.32^{\star *}$ & 0.03 & -0.01 & 0.13 & 0.05 & -0.22 & -0.17 & -0.11 & 0.02 & -0.09 & -0.05 & -0.09 \\
\hline $\begin{array}{l}\text { Week } 12 \\
\text { diurnal } \\
\text { category }\end{array}$ & & - & 0.23 & $0.37^{\star *}$ & 0.19 & -0.09 & $0.31^{*}$ & $0.32^{*}$ & 0.24 & $0.33^{* *}$ & -0.16 & -0.23 & -0.06 & -0.05 & -0.15 & -0.21 & $-0.30^{*}$ & -0.23 & $-0.31^{*}$ & 0.18 & -0.22 \\
\hline $\begin{array}{l}\text { \#Fatigue } \\
\text { Points W2 }\end{array}$ & & & - & $0.70^{\star \star \star}$ & 0.00 & -0.23 & 0.16 & 0.16 & 0.04 & 0.19 & -0.08 & 0.00 & 0.08 & 0.01 & -0.09 & -0.03 & -0.19 & -0.03 & -0.08 & 0.00 & -0.11 \\
\hline $\begin{array}{l}\text { \#Fatigue } \\
\text { Points W12 }\end{array}$ & & & & - & 0.05 & -0.20 & 0.23 & 0.27 & -0.00 & $0.34^{* *}$ & -0.19 & -0.04 & 0.02 & 0.03 & 0.06 & -0.15 & -0.18 & 0.02 & -0.09 & 0.13 & -0.18 \\
\hline $\begin{array}{l}\text { Avg Fatigue } \\
\text { W2 }\end{array}$ & & & & & - & $0.29^{*}$ & 0.11 & 0.06 & 0.18 & 0.02 & -0.10 & 0.14 & 0.06 & 0.13 & -0.20 & -0.07 & 0.03 & 0.05 & -0.04 & -0.16 & 0.05 \\
\hline $\begin{array}{l}\text { Avg Fatigue } \\
\text { W12 }\end{array}$ & & & & & & - & 0.17 & 0.18 & 0.20 & -0.03 & -0.02 & 0.05 & -0.06 & -0.05 & $-0.28^{*}$ & -0.02 & 0.25 & 0.22 & $0.34^{* *}$ & $-0.36^{*}$ & 0.07 \\
\hline Age & & & & & & & - & $0.61^{* * *}$ & $0.65^{\star \star \star}$ & $0.35^{* *}$ & -0.15 & 0.02 & 0.01 & -0.05 & -0.03 & $-0.30^{*}$ & -0.19 & -0.16 & -0.08 & 0.04 & 0.03 \\
\hline Income & & & & & & & & - & $0.51^{* * *}$ & $0.33^{*}$ & -0.07 & $-0.30^{*}$ & -0.18 & -0.18 & -0.16 & -0.13 & -0.12 & -0.13 & -0.01 & 0.15 & -0.14 \\
\hline $\begin{array}{l}\text { Years of } \\
\text { education }\end{array}$ & & & & & & & & & - & 0.23 & -0.07 & $-0.25^{*}$ & -0.15 & $-0.29^{*}$ & 0.02 & $0.51^{* \star *}$ & -0.21 & -0.23 & -0.14 & 0.07 & 0.01 \\
\hline $\begin{array}{l}\text { Morningness- } \\
\text { Eveningness } \\
\text { Score }\end{array}$ & & & & & & & & & & - & -0.13 & -0.08 & -0.07 & -0.02 & -0.07 & -0.22 & -0.1 & -0.02 & -0.06 & 0.13 & -0.1 \\
\hline $\begin{array}{l}\text { Locus of } \\
\text { Control }\end{array}$ & & & & & & & & & & & - & 0.12 & 0.06 & 0.19 & -0.01 & 0.02 & 0.09 & -0.16 & 0.19 & 0.13 & 0.24 \\
\hline POMS W3 & & & & & & & & & & & & - & $0.72^{\star \star *}$ & $0.56^{\star \star *}$ & 0.05 & $0.27^{*}$ & $0.50^{\star \star \star}$ & $0.43^{* *}$ & $0.40^{\star *}$ & -0.2 & -0.03 \\
\hline BAI W2 & & & & & & & & & & & & & - & $0.54^{\star \star *}$ & 0.08 & 0.23 & $0.32^{*}$ & $0.37^{\star *}$ & 0.23 & 0.02 & 0.1 \\
\hline PSS W5 & & & & & & & & & & & & & & - & -0.02 & 0.23 & $0.33^{* *}$ & $0.32^{* *}$ & $0.42^{\star *}$ & -0.17 & -0.07 \\
\hline $\begin{array}{l}\text { Sleep } \\
\text { Efficiency W2 }\end{array}$ & & & & & & & & & & & & & & & - & -0.22 & 0.06 & -0.08 & 0.01 & $0.57^{\star \star *}$ & -0.16 \\
\hline $\begin{array}{l}\text { Sleep Onset } \\
\text { W2 }\end{array}$ & & & & & & & & & & & & & & & & - & 0.09 & 0.21 & 0.17 & $-0.45^{\star *}$ & 0.21 \\
\hline POMS W13 & & & & & & & & & & & & & & & & & - & $0.64^{\star \star \star}$ & $0.77^{\star \star \star *}$ & 0.03 & -0.21 \\
\hline BAI W12 & & & & & & & & & & & & & & & & & & - & $0.43^{* *}$ & -0.17 & -0.17 \\
\hline PSS W13 & & & & & & & & & & & & & & & & & & & - & -0.14 & -0.22 \\
\hline $\begin{array}{l}\text { Efficiency } \\
\text { W12 }\end{array}$ & & & & & & & & & & & & & & & & & & & & - & -0.1 \\
\hline $\begin{array}{l}\text { Sleep Onset } \\
\text { W12 }\end{array}$ & & & & & & & & & & & & & & & & & & & & & - \\
\hline
\end{tabular}

Notes:

${ }^{*}=p<0.05,{ }^{* *}=p<0.01,{ }^{* * *}=p<0.001$

Variables "Week 2" and "Week 12" are coded $0=$ no rhythm, $1=$ yes rhythm

Variable "Morningness-Eveningness Score": higher scores = more morning-type

Variable "Locus of Control": higher scores = external locus of control 
The model began with all 5 predictor variables in step one, and eliminated age, locus of control, years of education, and income respectively in subsequent steps. The only variable remaining in the fourth and final step was morningness-eveningness score, which predicted a significant amount of variation in diurnal rhythmicity category during week 2 (see Table 5). According to the odds ratio values, for every one point increase on the morningnesseveningness scale (indicating more morning-type chronotype), women were $19 \%$ more likely to have a diurnal rhythm at week 12. Therefore, the first hypothesis from research question 3 , that women with a diurnal rhythm would be more morning-type, was supported.

\section{Table 5}

Results for hypotheses from research questions 3 \& 4: Stepwise binary logistic regression with independent variables years of education, income, age, morningness-eveningness scores, and locus of control entered into the model.

\begin{tabular}{|c|c|c|c|c|c|}
\hline Predictors & $\beta$ & Wald & $\operatorname{Exp}(\beta)$ & $95 \% \mathrm{Cl}$ & $P$ \\
\hline $\begin{array}{l}\text { Final Step of } \\
\text { Model }\end{array}$ & & & & & 0.001 \\
\hline Age & 0.032 & & - & - & 0.237 \\
\hline Locus of Control & 0.075 & & - & - & 0.373 \\
\hline $\begin{array}{l}\text { Years of } \\
\text { Education }\end{array}$ & -0.126 & & - & - & 0.337 \\
\hline Income & 0.000 & & - & - & 0.290 \\
\hline $\begin{array}{l}\text { Morningness- } \\
\text { Eveningness } \\
\text { Score }\end{array}$ & 0.174 & 5.819 & 1.190 & $1.033-1.370$ & 0.016 \\
\hline
\end{tabular}

Hypothesis 2 for research question 3 that women with a diurnal rhythm would have higher internal locus of control scores was not supported. Neither was the first hypothesis from research question 4, that women with a diurnal rhythm would have higher annual household 
income supported. Also, the third hypothesis from research question 4 that women with a diurnal rhythm would be older was not supported.

\section{Results for Research Question 5}

Research Question 5: How does presence or absence of a diurnal rhythm relate to objectively estimated sleep efficiency at postpartum weeks 2 and $12 ?$

Hypothesis 1 was not supported. Women who had a diurnal rhythm did not have a higher sleep efficiency at either postpartum week $2, \mathrm{~F}(64)=3.07, p=0.085, d=0.46$, or week $12, \mathrm{~F}(50)=1.67, p=0.202$ (see Figures $3 \mathrm{a} \& \mathrm{~b}$ ).

(a.)

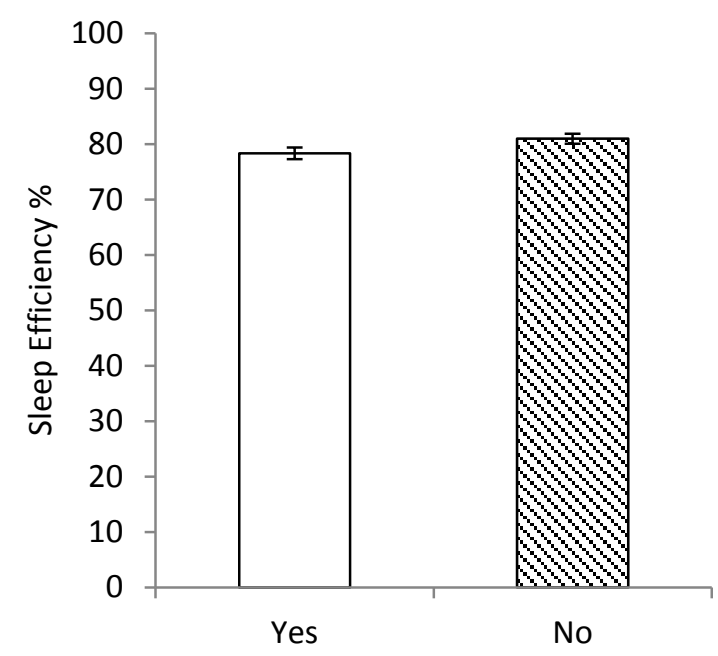

(b.)

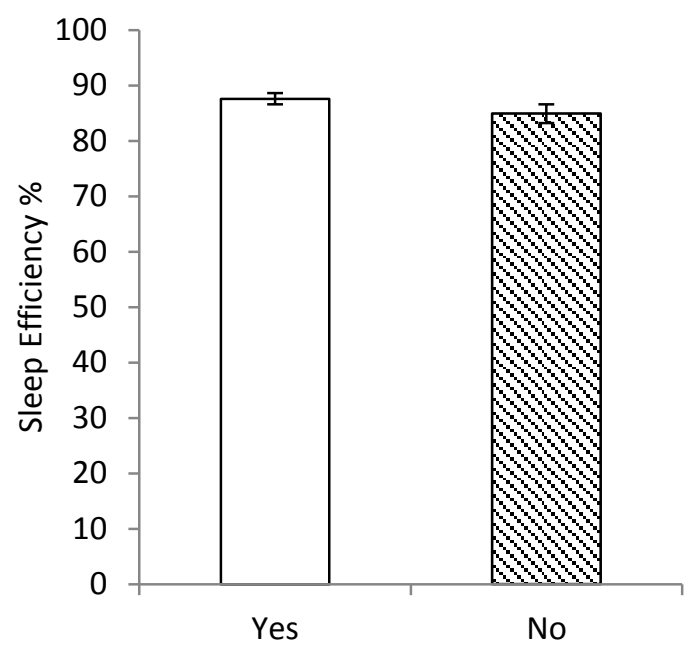

Figure 3. Diurnal rhythmicity at postpartum week 2 (a) and 12 (b) in relation to sleep efficiency.

\section{Results for Research Question 6}

Research Question 6: How does presence or absence of a diurnal rhythm relate to objectively estimated variance in sleep onset time at postpartum weeks 2 and 12 ? 
Hypothesis 1 was not supported. Women who had a diurnal rhythm did not have a less variable sleep onset time at either postpartum week $2, \mathrm{~F}(64)=1.79, p=0.186$, or week 12 , $F(50)=2.43, p=0.126$ (See figures $4 a \& b)$.

(a.)

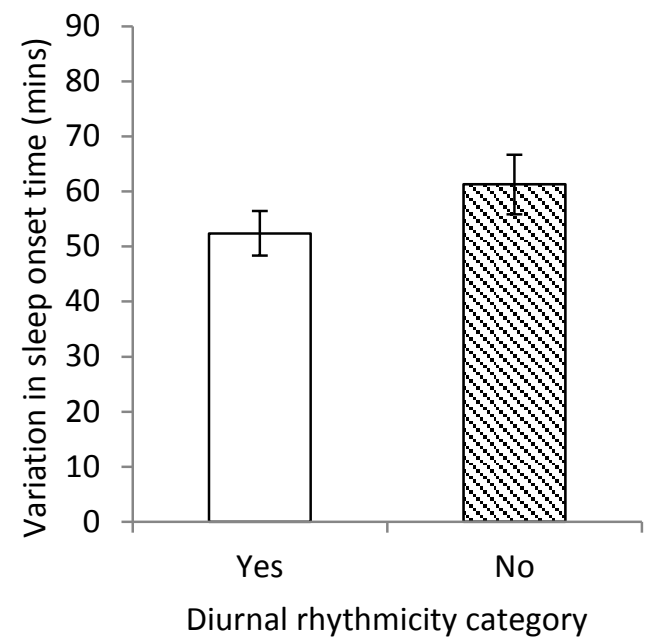

(b.)

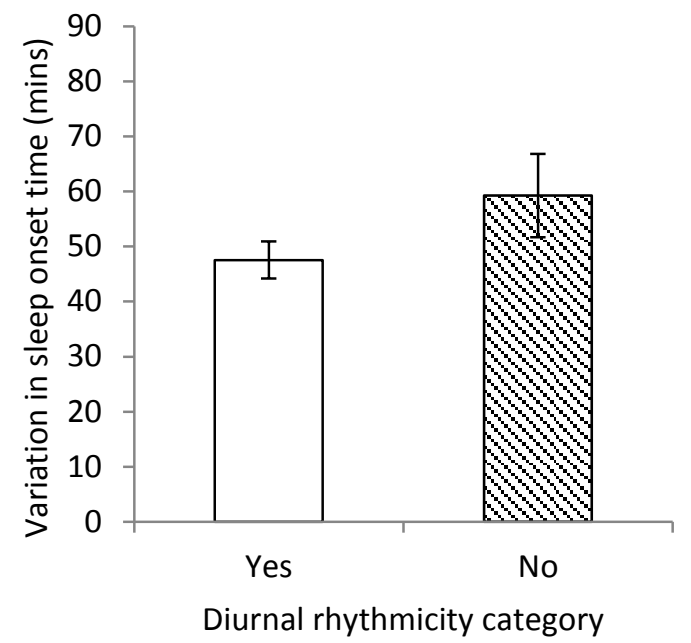

Figure 4 a \& b. Average variation in sleep onset time during week 2 (a) and week 12 (b) between women with and without a diurnal rhythm.

\section{Supplemental Analyses}

After finding significant differences between diurnal rhythmicity grouping and various demographic variables, Research Question 1 was retested accounting for measures of income and age, since both these values were significantly correlated with diurnal category at week 12 (see Table 4). However, missing data for the income variable reduced the $n$ 's for the analyses. Compared to the original ANOVAs, an additional $17.1 \%$ of participants (making the total sample analyzed $n=53$ ) were missing income values for postpartum week 2 , and an additional $15.0 \%$ of participants (making the total sample analyzed $n=51$ ) were missing income values for postpartum week 12. Two separate one-way ANCOVAs with diurnal rhythmicity category as the independent variable and POMS scores as the dependent variable, controlling for age and 
income, were conducted at each of postpartum weeks 2 and 12. At postpartum week 2, POMS scores were not related to diurnal rhythmicity category after accounting for age and income, $F(52)=0.49, p=0.485$, echoing the original one-way ANOVA result. However, at postpartum week 12 , POMS scores were no longer related to diurnal rhythmicity category after accounting for age and income, $\mathrm{F}(50)=3.60, p=0.064$.

POMS subscale scores were analyzed in ANCOVA models accounting for age and income with diurnal rhythmicity as the independent variable. The POMS was broken down into its 6 subscales: tension-anxiety, depression, anger-hostility, vigor-activity, fatigue, and confusion-bewilderment. Significant differences were found in these ANCOVAs on the vigoractivity and confusion-bewilderment subscales. At postpartum week 12, women with a rhythm reported more vigor-activity than those without a rhythm, $\mathrm{F}(48)=4.97, p=0.031, d=0.75$. Women with a rhythm reported less confusion-bewilderment than those without a rhythm at postpartum week 12, $\mathrm{F}(48)=6.07, p=0.018, d=0.78$ (see Figure 5). 


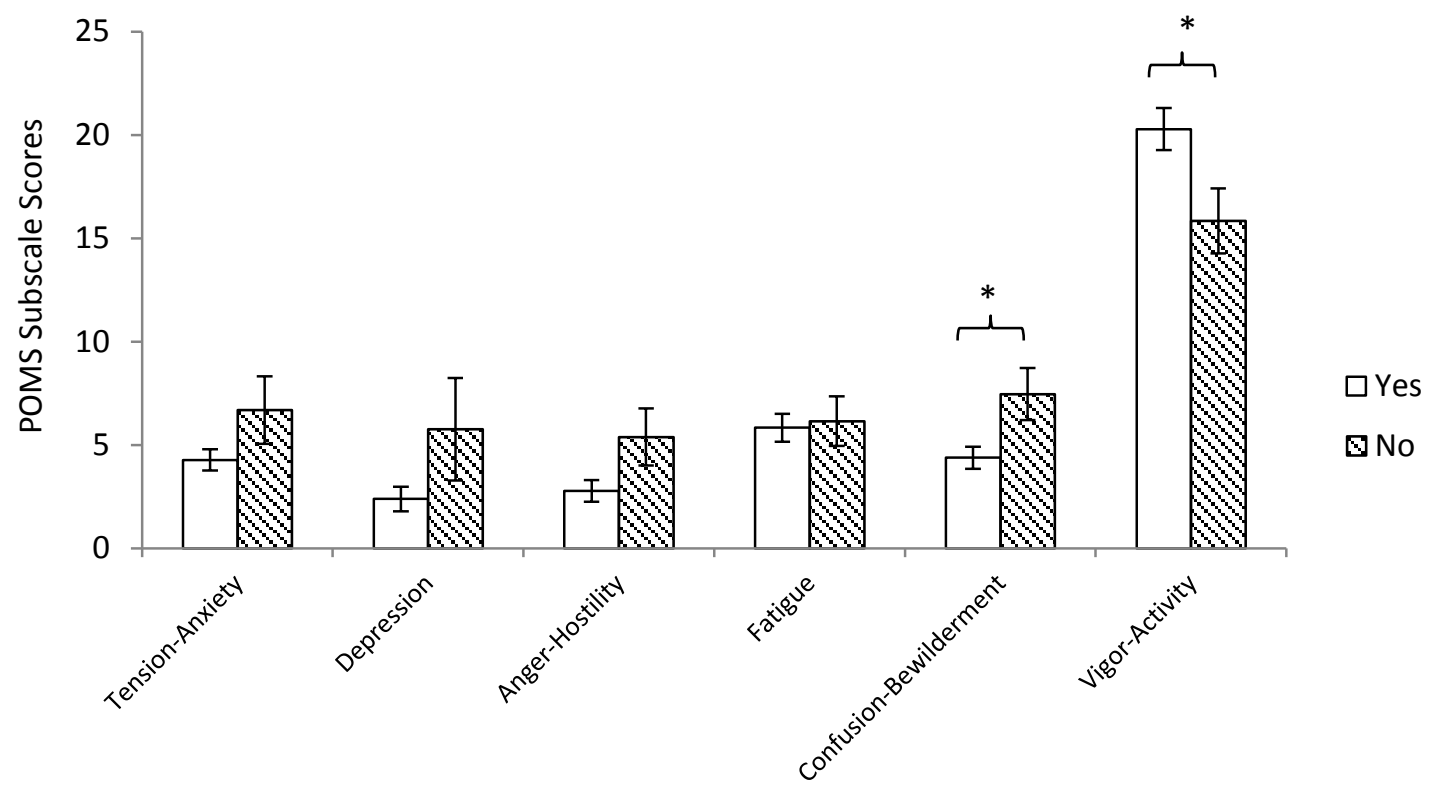

Diurnal Rhythmicity Category

Figure 5. Diurnal rhythmicity at postpartum week 12 and corresponding average POMS subscale scores.

${ }^{*}=p<0.05$

\section{Beck Anxiety Inventory and Perceived Stress Scale}

In addition to the originally planned analyses, anxiety and stress scores were examined in relation to diurnal rhythmicity category at postpartum weeks 2 and 12. The Beck Anxiety Inventory (BAl) has been used in postpartum women to screen for anxiety (Stuart, Couser, Schilder, O'Hara, \& Gorman, 1998). The BAl is a 21 -item survey where participants are asked to respond to each item on a $0-3$ scale. The perceived stress scale (PSS) is a 10-item questionnaire measuring the degree to which life situations are considered to be stressful. This scale has been used in postpartum women to examine correlations with depression (Boury, Larkin, \& Krummel, 2004; Dennis \& Boyce, 2004). A correlation matrix between the POMS total mood disturbance score, BAI, and PSS found all were significantly correlated with each other, as seen in Table 4. 


\section{Beck Anxiety Inventory (BAI)}

Two separate one-way ANCOVAs with diurnal rhythmicity category as the independent variable and $\mathrm{BAI}$ scores as the dependent variable controlling for age and income were conducted at each of postpartum weeks 2 and 12. At postpartum week 2, Levene's test of homogeneity of variance was satisfied $(p>0.001)$, and BAI score was not related to diurnal rhythmicity category after accounting for age and income, $\mathrm{F}(53)=0.70, p=0.407$. At postpartum week 12, Levene's test of homogeneity of variance had a value of $p=0.002$, suggesting we need to be cautious interpreting our results because there may be issues with homogeneity of variance. Women with diurnal rhythms had significantly better BAI scores $(M=$ 2.11, $S E=0.45)$ than mothers without diurnal rhythms at week $12(M=4.86, S E=1.23), F(50)=$ 6.41, $p=0.015, d=0.72$ (see Figure $6 a \& b$ ).

(a.)

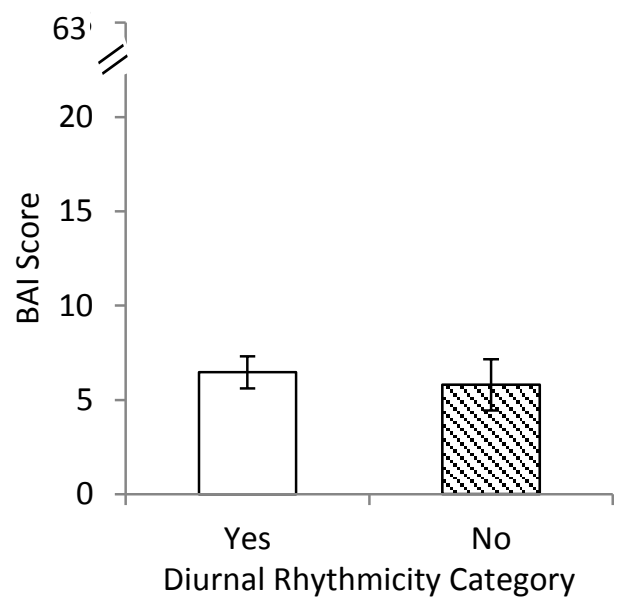

(b.)

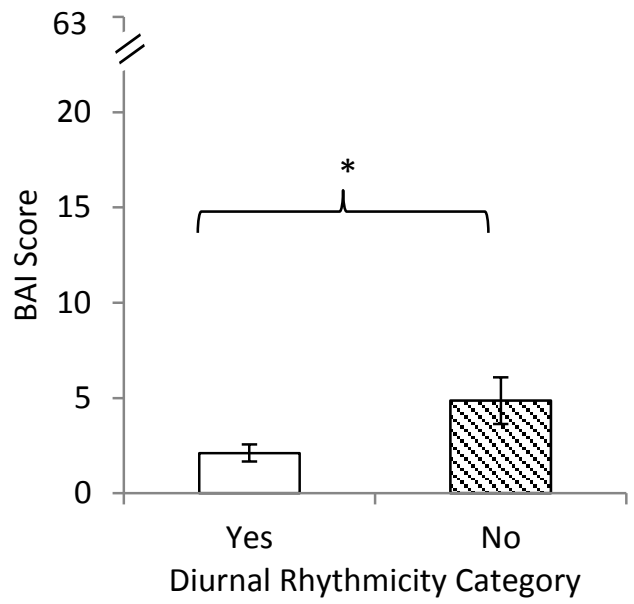

Figure 6 a\&b. Diurnal rhythmicity at postpartum week 2 (a) and week 12 (b) and corresponding average BAI scores.

${ }^{*}=p<0.05$ 


\section{Perceived Stress Scale (PSS)}

Two separate one-way ANCOVAs with diurnal rhythmicity category as the independent variable and PSS scores as the dependent variable controlling for age and income were conducted at each of postpartum weeks 2 and 12. Both analyses satisfied Levene's test of homogeneity of variance $(p>0.001)$. There was no statistically significant difference between diurnal categories and stress at week $2, \mathrm{~F}(52)=0.41, p=0.526$. However, women with diurnal rhythms reported significantly less stress $(M=8.65, S E=2.81)$ than mothers without diurnal rhythms at week $12(M=12.54, S E=6.62), F(49)=5.27, p=0.026, d=0.70$ (see Figure 7 $a \& b)$.

(a.)

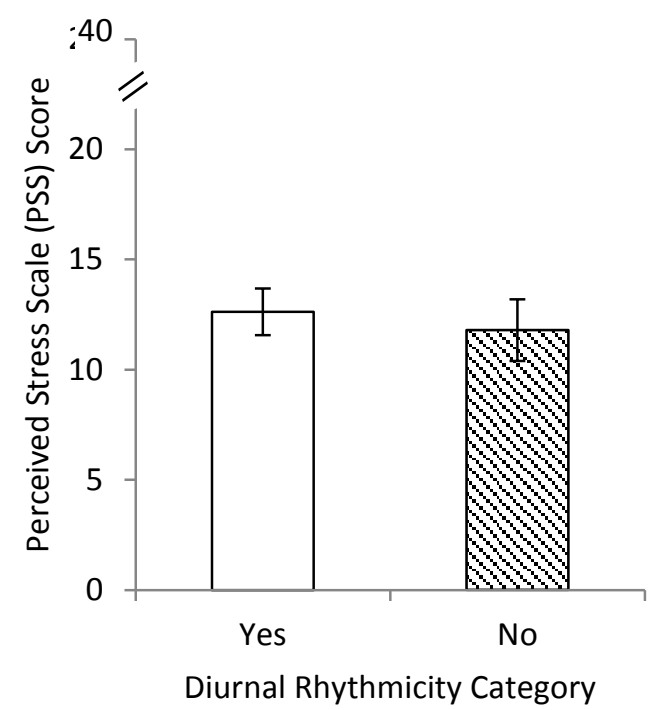

(b.)

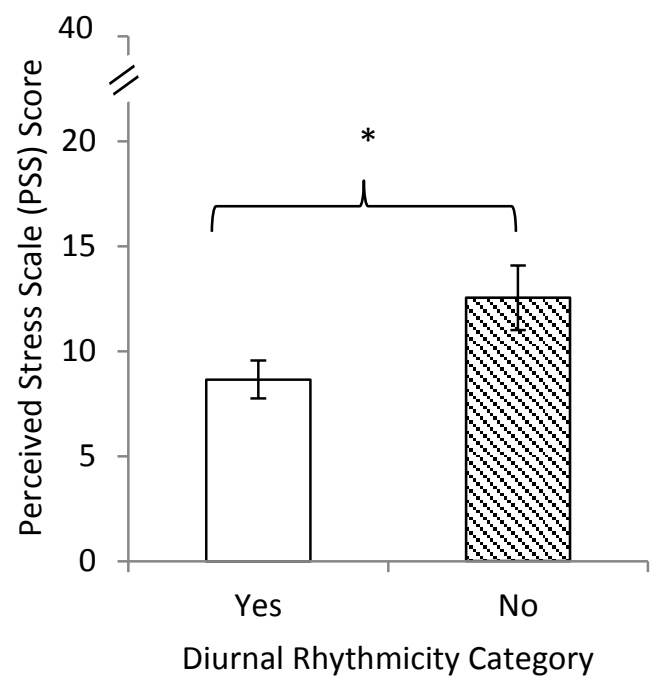

Figure 7 a\&b. Diurnal rhythmicity at postpartum week 2 (a.) and week 12 (b.) and corresponding average PSS scores.

${ }^{*}=p<0.05$

Finally, where hypotheses 3 and 4 tested for correlations between various predictor variables and diurnal rhythmicity at postpartum week 2 using a backward stepwise logistic 
regression model, supplemental analyses used the same model to test the influence of the same variables on diurnal rhythmicity at postpartum week 12. Descriptive statistics are reported in Table 6.

The model began with all 5 predictor variables in step one, and eliminated years of education, income, and locus of control respectively in subsequent steps. The variables remaining in the fourth and final step were age and morningness-eveningness score, with both variables predicting a significant amount of variation in diurnal rhythmicity category during week 12 (see Table 7). According to the odds ratio values, for every year older, women were $24 \%$ more likely to have a diurnal rhythm at week 12 . Also, for every one point increase on the morningness-eveningness scale (indicating more morning-type), women were $21 \%$ more likely to have a diurnal rhythm at week 12 .

Table 6

Descriptive statistics of variables in the regression model

\begin{tabular}{|c|c|c|c|c|}
\hline \multirow[b]{3}{*}{ Variable } & \multicolumn{4}{|c|}{ Diurnal Rhythmicity Category } \\
\hline & \multicolumn{2}{|c|}{ Yes } & \multicolumn{2}{|c|}{ No } \\
\hline & Mean & $\begin{array}{l}\text { Standard } \\
\text { Deviation }\end{array}$ & Mean & $\begin{array}{l}\text { Standard } \\
\text { Deviation }\end{array}$ \\
\hline Income* & $67,000^{*}$ & 35,000 & $43,000^{*}$ & 26,000 \\
\hline $\mathrm{Age}^{*}$ & $27.44^{*}$ & 3.96 & $24.28^{*}$ & 2.72 \\
\hline Years of Education & 16.71 & 2.38 & 15.11 & 2.84 \\
\hline $\begin{array}{c}\text { Morningness-Eveningness } \\
\text { Score }\end{array}$ & $20.26^{\star *}$ & 4.55 & $16.07^{* \star}$ & 3.97 \\
\hline Locus of Control & 9.50 & 3.78 & 11.14 & 3.53 \\
\hline
\end{tabular}

\footnotetext{
${ }^{*}=p<0.05$

${ }^{* *}=p<0.01$

${ }^{* * *}=p<0.001$
} 


\section{Table 7}

Stepwise binary logistic regression with independent variables years of education, income, age, morningness-eveningness scores, and locus of control entered into the model

\begin{tabular}{|c|c|c|c|c|c|}
\hline Predictors & $\beta$ & Wald & $\operatorname{Exp}(\beta)$ & $95 \% \mathrm{Cl}$ & $P$ \\
\hline $\begin{array}{l}\text { Final Step of } \\
\text { Model }\end{array}$ & & & & & 0.001 \\
\hline $\begin{array}{l}\text { Years of } \\
\text { Education }\end{array}$ & 0.067 & & - & - & 0.720 \\
\hline Income & 0.000 & & - & - & 0.596 \\
\hline Locus of Control & -0.076 & & - & - & 0.467 \\
\hline Age & 0.215 & 3.919 & 1.240 & $1.002-1.535$ & 0.048 \\
\hline $\begin{array}{l}\text { Morningness- } \\
\text { Eveningness } \\
\text { Score }\end{array}$ & 0.192 & 4.854 & 1.211 & $1.021-1.437$ & 0.028 \\
\hline
\end{tabular}

\section{Morningness-Eveningness Scores}

A $2 \times 2$ ANOVA was conducted with rhythmicity at postpartum week 2 by rhythmicity at postpartum week 12 and morningness-eveningness scores as the dependent variable and found to be significant, $F(54)=3.84, p=0.014$. To find out exactly where the differences lay, one-way ANOVAs were conducted on morningness-eveningness scores between each of the four possible categories (Yes-Yes, No-No, Yes-No, No-Yes). Women in the Yes-Yes category were more morning-type than women in the No-No category, $F(34)=10.18, p=0.003$. Women in the No-Yes category were also significantly more morning-type than women in the No-No category, $\mathrm{F}=4.686, p=0.041$ (see Figure 8 ). 


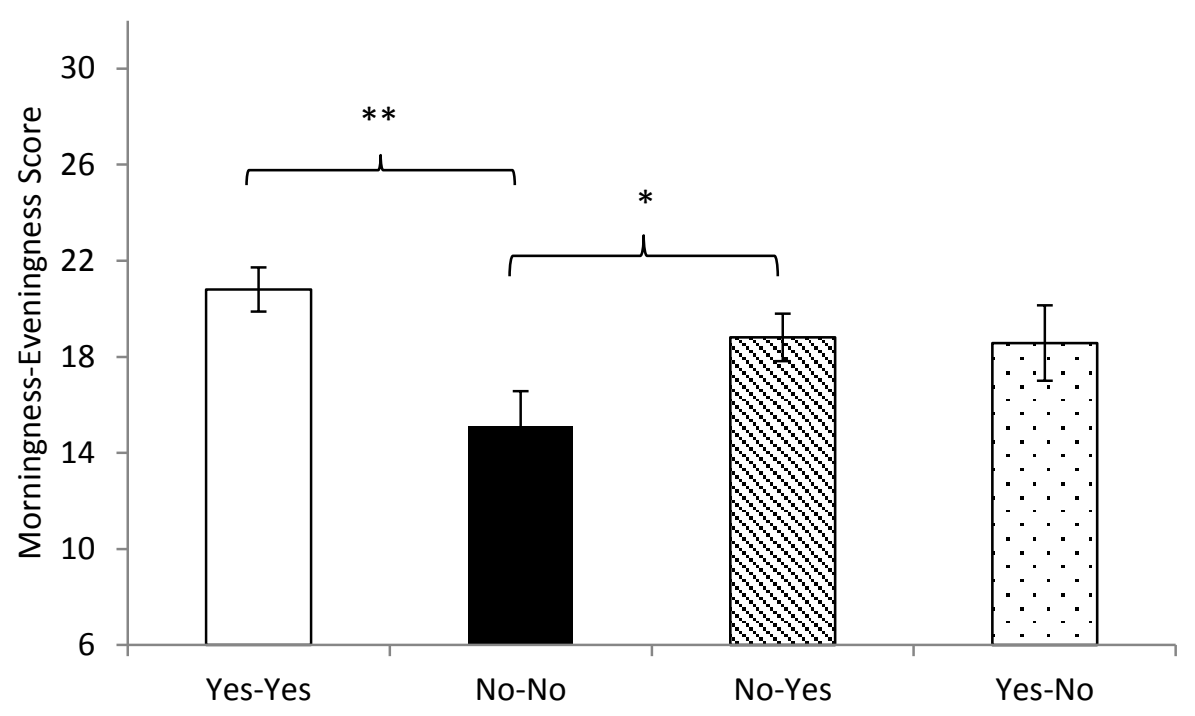

Figure 8. Diurnal rhythmicity category at each postpartum week and corresponding average Morningness-Eveningness scores.

${ }^{*}=p<0.05$

${ }^{* *}=p<0.01$

\section{Average Fatigue Scores}

The average fatigue scores across each of postpartum weeks 2 and 12 were also examined for women in relation to other variables (see Table 4). Correlations between fatigue scores at week 2 and 12 were significant within women, $r=0.29, p=0.024$. In addition, higher self-reported fatigue at week 12 was significantly associated with a lower sleep efficiency at week 2, $r=-0.28, p=0.033$, as well as a lower sleep efficiency at week $12, r=-0.36, p=0.010$. Higher self-reported fatigue at week 12 was also significantly correlated with more stress at week $13, r=0.34, p=0.007$

\section{Discussion}

The major goal of this study was to examine presence of diurnal rhythmicity in relation to mood, sleep efficiency, and stability of sleep onset times among postpartum women in the early 
and later postpartum periods. In addition, demographic information and locus of control and morningness-eveningness traits were examined in an attempt to identify variables that may help predict development of a rhythm in the postpartum period. Additional supplemental analyses sought to examine the relation between diurnal rhythmicity and levels of anxiety and stress.

\section{Mood}

Results from this study indicate that mood, as scored through the POMS total mood disturbance, does not differ between mothers with a diurnal rhythm compared to those without a rhythm at postpartum week 2 . This is not surprising considering that $30-75 \%$ of women experience the "baby blues" during the first postpartum weeks (Seyfried \& Marcus, 2003). However, at postpartum week 12, a significant difference in mood scores was found between rhythmicity categories. Mothers with a diurnal rhythm had an average score of 1.67 (lower scores are indicative of better mood), whereas mothers without a diurnal rhythm averaged a 16.63. A validation study of the POMS on a healthy population of 208 women found the average score to be 20.3 , but with large variability $(S D=33.1$ ) (Nyenhuis, Yamamoto, Luchetta, Terrien, \& Parmentier, 1999). Interestingly, this suggests postpartum women are reporting better mood than the average woman.

After adding covariates of age and income into the model, the significant difference in mood at postpartum week 12 was lost, suggesting at least part of the difference found in mood between these women was attributed to age and income. Older women and those with a higher annual household income reported better mood. The effect size for the ANCOVA was moderate $(d=0.61)$. However, it should also be noted that due to missing data on the income variable, the number of participants included in the ANCOVA $(n=51)$ was fewer than the number of participants included in the original ANOVA $(n=60)$, and the overall power achieved was only 0.46. The income variable accounted for more of the shared variance than age in the ANCOVA 
model. However, when each variable was entered as individual covariates in separate models, they both accounted for enough variance to eliminate the significant difference in mood. Interestingly, neither the correlation between age and mood or between income and mood was significant at week 12 .

Further analyses divided the POMS scores into their respective subcategories. It was found that women with a diurnal rhythm reported more vigor-activity and less confusionbewilderment than those without a rhythm, after accounting for age and income. This suggests the relation between rhythmicity category and the vigor-activity and confusion-bewilderment subscales of the POMS was not affected by age and income to the same degree as the total POMS score.

Speculation of the relation between these variables came to the conclusion that it is possible, since higher income and age are related to having a rhythm, these women might have been able to afford assistance in caregiving that is allowing them to better adjust to the postpartum period. It is also a possibility that women with a lower household income may have lead more challenging lives during the time of their transition to parenthood, and this may have influenced their ability to maintain a rhythm. Age may have played a role because younger mothers may struggle with different challenges than older mothers. It is speculated that younger mothers may have fewer friends with children due to a younger cohort of friends, which may have resulted in less social support and assistance from this particular social network.

Supplemental analyses also looked at the relation between diurnal rhythmicity and anxiety as well as rhythmicity and perceived stress scores. While correlations between mood, anxiety, and stress scores were all significant, their correlations ranged between 0.428 and 0.771. According to Cohen (1988), these range between moderate to large effect sizes, which were lower correlations than would have been expected for these measures, since the POMS 
score comprises subscales measuring anxiety and aspects that can affect stress. Therefore, anxiety and stress relation between rhythmicity categories were examined.

Analyses found similar relations with these scores for stress and anxiety as was found for mood. At postpartum week 2 , there was no difference in diurnal rhythmicity category and levels of stress and anxiety after accounting for income and age. However, at postpartum week 12, after accounting for income and age, mothers with a diurnal rhythm reported significantly less stress and anxiety than mothers without a diurnal rhythm. These results suggest a relation between having a diurnal rhythm in the later postpartum period and reduced levels of anxiety and stress. Both maternal stress and anxiety have negative influences on the development of the child (Correia \& Linhares, 2007; Fowles \& Walker, 2009; Glasheen, Richardson, \& Fabio, 2010; Walker \& Cheng, 2007). Greater maternal anxiety is associated with lower infant developmental scores (Correia \& Linhares, 2007). Relations have been found between higher maternal anxiety and depression and increases in difficulty temperament of the baby (Correia \& Linhares, 2007). Other studies indicated a relation between postpartum maternal anxiety and child behavioral problems (Glasheen et al., 2010). In addition, maternal postpartum stress directly associates with child behavior problems (Walker \& Cheng, 2007). Increases in maternal stress as measured by the Perceived Stress Scale at the sixth month postpartum also significantly relates to decreases in reported infant health at 18 months of age (Fowles \& Walker, 2009).

The present study also was interested in whether changes in diurnal rhythmicity from postpartum week 2 to week 12 were associated with changes in mood. After dividing the mothers into four groups based on their rhythmicity category at postpartum week 2 and 12 , only mothers in the Yes-Yes group (having a significant rhythm at both postpartum weeks 2 and 12) showed any significant change in mood. This change had a large effect size $(d=0.79)$ and was in the direction of an improvement in mood scores from postpartum weeks 2 to 12 . Based on 
the high prevalence of postpartum blues in the first couple of postpartum weeks, an improvement in mood was expected (Ross et al, 2005; Seyfried \& Marcus, 2003). Women falling into the other grouping categories did not show significant changes in mood in either direction, which may be due to the small number of women in each category. Interestingly, the 8 women in the No-No group (not having a significant rhythm at either postpartum week 2 or 12), showed a statistically non-significant improvement in mood, but with a large effect size $(d=$ 0.86). This improvement in mood was unexpected and contradicts the original hypothesis that women in the No-No category would show a worsening in mood scores over time. Perhaps this improvement in mood is also reflective of a generally more negative mood in many postpartum women at week 2 due to postpartum blues. A larger sample size for this group of women would provide a more complete understanding of these relations.

\section{Objective Sleep Data}

The changes in rhythmicity at both postpartum weeks 2 and 12 were assessed in relation to sleep variables, such as sleep efficiency and variations in sleep onset time. Neither sleep efficiency nor variation in sleep onset time was significantly different between rhythmicity categories at either weeks 2 or 12 . While variations in sleep onset times between the two rhythmicity categories was not significantly different, the values were in the hypothesized direction (women with a rhythm had lower variations in sleep onset time). The lack of difference in sleep onset time variation was somewhat surprising considering that the disruption in circadian rhythm can lead to irregular and spontaneous sleep-wake times (Kanathur, Harrington, \& Lee-Chiong, 2010). However, there may be external factors that are masking this difference in sleep onset variation including some mothers going back to work during the study. Exact data on when mothers returned to work was not obtained, so this could not be taken into consideration in the present study. In addition, taking into consideration the sample size of each group analyzed and the effect size found, post hoc power analyses for postpartum week 12 
discovered a power of only 0.33 . This small power suggests there may be an effect that was missed in this study due to a small sample size.

\section{Predictors of Diurnal Rhythmicity Category}

The third and fourth research questions, and some supplemental analyses, were interested in what demographic variables and survey outcomes might be highly correlated with diurnal rhythmicity category. The research questions sought to predict rhythmicity category at the early postpartum period (week 2), and regression analyses were run to determine which variables were significantly correlated with rhythmicity category over and above the other variables in the model. Only scores on the morningness-eveningness scale were highly correlated with rhythmicity category at postpartum week 2 . It was in the hypothesized direction, so women who were more morning-type according to the survey scores were significantly more likely to have a significant rhythm. This supports the finding by Taillard, Philip, and Bioulac (1999) that individuals who were more morning-type were more likely to keep a stable sleepwake schedule that is characteristic of a stable circadian rhythm. This pattern may be due to social constraints that cause evening-type individuals to wake up earlier than desired during the work week, and consequently try to go to sleep earlier, while reverting back to their late evening patterns on the weekends. It is speculated that since weekday work schedules are generally better suited to morning-type individuals, they likely do not experience the same constraints, and are better able to maintain a stable sleep-wake schedule.

However, considering that differences in mood scores between diurnal categories were only found at week 12 , it seemed even more important to examine factors that might predict rhythmicity category at postpartum week 12 . The same regression model was run in the supplemental analyses, but adding in the demographic and survey variables to find correlations at week 12. As with the model at week 12, morningness-eveningness scores were significantly 
correlated with rhythmicity category, with morning-types being more likely to have a diurnal rhythm at week 12 . In addition, age was also significantly correlated with diurnal category, with older women being more likely to have a rhythm at week 12 . This is in the hypothesized direction, as some of the women in this study were still young enough to be experiencing a circadian rhythm shift that occurs naturally during adolescence, and does not shift back until the early to mid-twenties (Roenneberg et al., 2004). The fact younger women in this study may still be experiencing this delayed sleep phase or may be in the process of transitioning into their normal adult sleep phase explains why they were more likely to have a rhythm disruption.

An interesting point can be made regarding the correlation matrix that was examined prior to conducting these regression analyses. Diurnal category at week 2 was not significantly correlated with diurnal category at week 12 . This is interesting as there were significant correlations between morningness-eveningness scores and diurnal category at both weeks, suggesting those postpartum women who changed categories may have been those women who were near the mean of the total sample's morningness-eveningness scores, which would indicated neither morning- or evening-type. Supplemental analyses examined the relation between varying diurnal categories at each postpartum week and scores on the morningnesseveningness scale in an attempt to explain this relation. As expected, the women in the Yes-Yes category were significantly more morning-type than women in the No-No category. According to the classification scale by Horne \& Ostberg, the mean value of women in the Yes-Yes category falls in the "neither type" category, while the mean value of women in the No-No category falls in the "moderately evening type" category. Women who changed categories (Yes-No and No-Yes) had mean values falling in between those of the Yes-Yes and No-No women. Women in the NoYes category had significantly higher scores than women in the No-No category. However, the mean values of women in the Yes-Yes, Yes-No, and No-Yes category all fell into "neither type," meaning they were neither morning- or evening-type. So perhaps it is not that women with a 
rhythm were more morning-type, but actually that women without a rhythm were more eveningtype.

\section{Limitations}

A major limitation of this study was the small sample size in some groups, especially for research question 2 that analyzed effects of changes in rhythmicity within groups from the early to later postpartum period. In addition, when determining the diurnal rhythmicity category for each women, there was a large range in the number of fatigue points that contributed to categorization (from 4-44). Many women did not adhere to instructions to fill out the fatigue reports 3-4 times a day, and as a result had fewer fatigue scores. These women may not have had enough data to allow statistical detection of a rhythm, and as a result some women may have been improperly categorized.

The larger study did not include information regarding the infant's night awakenings. The number of times the infant awoke at night is presumed to have played a large role in disruption of the mother's rhythm as well as her mood. Information regarding the role of other caregivers attending to infants at night would also help elucidate the full picture.

Nor was there information about the participants' sleep and fatigue prior to the birth of their infant. Thus, there is no information on individual differences in ability to maintain a diurnal rhythm prior to the postpartum period. It is possible that some of these women had a disruption in their rhythm due to individual physiological or behavioral differences independent of postpartum disruption in their sleep wake cycle. It is also possible that sleep disruption during pregnancy in varying degrees in these women caused a buildup of sleep debt that contributed to a diurnal rhythm disruption. 
Finally, there may have been seasonal influences with variation in rhythmicity grouping. The importance of the light-dark cycle in entraining rhythms is well known, as is the seasonal effects of circadian rhythmicity (Czeisler et al, 1986; Roenneberg, Hut, Daan, \& Merrow, 2010). It is possible that women were more likely to display a disruption in this rhythm as a result of seasonal variation and a shortened day length after daylight saving time ends.

\section{Future Directions}

Future research should assess the seasonal variation of rhythmicity groups to evaluate any effects on establishment of a rhythm as a result of changes in the light-dark cycle due to winter/summer and daylight saving time.

Future studies should also use a larger sample size to achieve higher statistical power for some of the analyses. Furthermore, more objective measures for diurnal rhythmicity categorizing should be employed, such as measurements of melatonin levels, salivary cortisol, or body temperature throughout the day (Hofstra \& de Weerd, 2008). Since these measurements are objective, they may provide a more reliable method of categorizing women into diurnal rhythm grouping than the subjective measure of self-reported fatigue used in the present study.

Additionally, due to the significant role light plays on entraining the circadian rhythm, future studies could also analyze the effects of illumination levels at night on maintaining a significant rhythm. Perhaps postpartum women would be less likely to experience a disruption in their rhythm if they only turned on very dim lights during nocturnal awakenings. It would also be helpful to the field to have normative data regarding the participants' sleep and fatigue prior to the postpartum period, to ensure that differences found in diurnal rhythmicity are truly due to postpartum disruption rather than to individual differences. 
Finally, it would be interesting to look at this issue from a family dynamics perspective. Measuring the infant's sleep as well as the father's (or other nightly caretaker's) might help us understand the bigger picture of contributions to a disruption in the mother's rhythm.

\section{Conclusion}

Due to nocturnal demands placed on mothers in the postpartum period, the sleep-wake cycle is interrupted, placing postpartum women at risk for developing a circadian rhythm disruption. The present study sought to analyze women who develop a disruption on their rhythm at different postpartum periods. No difference in mood, anxiety, or stress was found at postpartum week 2 , but women with a disruption in their rhythm at postpartum week 12 showed significantly higher levels of anxiety and stress, even after controlling for demographic variables. Significant mood disruptions were also present, but this was nullified when demographic covariates were included. No differences were found between groups in relation to sleep efficiency and variation of sleep onset time at either postpartum week. Finally, age and circadian type were found to be significantly related to developing a rhythm at postpartum week 12 , suggesting that younger women and morning-type women are less likely to experience a disruption in their rhythm postpartum. These findings have implications for the understanding of mood disruption in healthy postpartum women, as well as providing the possibility of using assessments of circadian rhythm amplitude as a tool for screening women for postpartum anxiety, stress, and mood disorders. 


\section{References}

Aschoff, J. (1965). Circadian rhythms in man. Science, 148, 1427-1432.

Auger, R.R. \& Morgenthaler, T.I. (2009). Jet lag and other sleep disorders relevant to the traveler. Travel Medicine and Infectious Disease, 7, 60-68.

Babkoff, H., Caspy, T., \& Mikulincer, M. (1991). Subjective sleepiness ratings: The effects of sleep deprivation, circadian rhythmicity and cognitive performance. Sleep, 14, 534-539.

Banks, S. \& Dinges, D.F. (2007). Behavioral and physiological consequences of sleep restriction. Hournal of Clinical Sleep Medicine, 3, 519-528.

Bennett, S., Alpert, M., Kubulins, V., \& Hansler, R.L. (2009). Use of modified spectacles and light bulbs to block blue light at night may prevent postpartum depression. Medical Hypotheses, 73, 251-253.

Benson, K., Friedman, L., Noda, A., Wicks, D., Wakabayashi, E., \& Yesavage, J. (2004). The measurement of sleep by actigraphy: Direct comparison of 2 commercially available actigraphs in a nonclinical population. Sleep, 27, 986-989.

Bonnet, M.H. (1985). Effect of sleep disruption on sleep, performance, and mood. Sleep, 8, 1119.

Bonnet, M.H. \& Arand, D.L. (2003). Clinical effects of sleep fragmentation versus sleep deprivation. Sleep Medicine Reviews, 7, 297-310.

Borbély, A.A. (1982). Two process model of sleep regulation. Human Neurobiology, 1, 195-204.

Boury, J.M., Larkin, K.T., Krummel, D.A. (2004). Factors related to postpartum depressive symptoms in low-income women. Women \& Health, 39, 19-34. 
Cajochen, C., Jewett, M.E., \& Dijk, D-J. (2003). Human circadian melatonin rhythm phase delay during a fixed sleep-wake schedule interspersed with nights of sleep deprivation. Journal of Pineal Research, 35, 149-157.

Castillo, M.R., Hochstetler, K.J., Tavernier, R.J. Jr., Greene, D.M., \& Bult-Ito, A. (2004). Entrainment of the master circadian clock by scheduled feeding. The American Journal of Physiology-Regulatory, Intergrative and Comparative Physiology, 287,R551-R555.

Chaudron, L.H., Klein, M.H., Remington, P., Palta, M., Allen, C., \& Essex, M.J. (2001). Predictors, prodromes and incidence of postpartum depression. Journal of Psychosomatic Obstetrics \& Gynecology, 22, 103-112.

Cohen, J. (1988). Statistical power analysis for the behavioral sciences (2nd edition). Hillsdale, NJ: Erlbaum.

Correia, L.L. \& Linhares, M.B.M. (2007). Maternal anxiety in the pre- and postnatal period: A literature review. Revista Latino-Americana de Enfermagem, 15, 677-83.

Cuninkova, L. \& Brown, S.A. (2008). Peripheral circadian oscillators. Annals of the New York Academy of Sciences, 1129, 358-370.

Czeisler, C.Z., Allan, J.S., Strogatz, S.H., Ronda, J.M., Sánchez, R., Ríos, C.D., et al. (1986). Science, 233, 667-671.

Czeisler, C.A., Duffy, J.F., Shanahan, T.L., Brown, E.N., Mitchell, J.F., Rimmer, D.W., et al. (1999). Stability, precision, and near-24-hour period of the human circadian pacemaker. Science, 284, 2177-2181.

de Weerd A.W. \& van den Bossche, R.A.S. (2003). The development of sleep during the first months of life. Sleep Medicine Reviews, 7, 179-191. 
Dennis, C.-L. \& Boyce, P. (2004). Further psychometric testing of a brief personality scale to measure vulnerability to postpartum depression. Journal of Psychosomatic Obstetrics \& Gynecology, 25, 305-311.

Dijk, D-J. \& Archer, S.N. (2010). PERIOD3, circadian phenotypes, and sleep homeostasis. Sleep Medicine Reviews, 14, 151-160.

Dijk, D-J. \& von Schantz, M. (2005). Timing and consolidation of human sleep, wakefulness, and performance by a symphony of oscillators. Journal of Biological Rhythms, 20, 279290.

Edinger, J.D., Means, M.K., Stechuchak, K.M., \& Olsen, M.K. (2004). A pilot study of inexpensive sleep-assessment devices. Behavioral Sleep Medicine, 2, 41-49.

Field, T. (2010). Postpartum depression effects on early interactions, parenting, and safety practices: A review. Infant Behavior and Development, 33, 1-9.

Fisher, J.R.W., Feekery, C.J., \& Rowe-Murray, H.J. (2002). Nature, severity and correlates of psychological distress in women admitted to a private mother-baby unit. Journal of Paediatrics and Child Health, 38, 140-145.

Fowles, E. \& Walker, L.O. (2009). Maternal predictors of toddler health status. Journal for Specialists in Pediatric Nursing, 14, 33-40

Franken, P. \& Dijk, D-J. (2009) Circadian clock genes and sleep homeostasis. European Journal of Neuroscience, 29, 1820-1829.

Galler, J.R, \& Harrison, R.H. (2000). Maternal depressive symptoms affect infant cognitive development in Barbados. Journal of Child Psychology and Psychiatry, 41, 747-757. 
Galler, J.R, Harrison, R.H., Ramsey, F.C., Butler, S., \& Forde, V. (2004). Postpartum maternal mood, feeding practices and infant temperament in Barbados. Infant Behavior \& Development, 27, 267-287.

Gay, C.L., Lee, K.A., \& Lee, S. (2004). Sleep patterns and fatigue in new mothers and fathers. Biological Research for Nursing, 5, 311-318.

Glasheen, C., Richardson, G.A., \& Fabio, A. (2010) A systematic review of the effects of postnatal maternal anxiety on children. Archives of Women's Mental Health, 13, 61-74.

Golombek, D.A. \& Rosenstein, R.E. (2010). Physiology of circadian entrainment. Physiological Reviews, 90, 1063-1102.

Groer, M., Davis, M., \& Steele, K. (2004). Associations between human milk SlgA and maternal immune, infectious, endocrine, and stress variables. Journal for Human Lactation, 20, 153-158.

Gvilia, I. (2010). Underlying brain mechanisms that regulate sleep-wakefulness cycles. International Review of Neurobiology. 93, 1-21.

Hayes, B.A., Muller, R., \& Bradley, B.S. (2001) Perinatal depression: A randomized controlled trial of an antenatal education intervention for primiparas. Birth, 28,28-35.

Hofstra, W.A. \& de Weerd, A.W. (2008) How to assess circadian rhythm in humans: A review of literature. Epilepsy \& Behavior, 13, 438-444.

Horne, J.A. \& Östberg, O. (1976). A self-assessment questionnaire to determine morningnesseveningness in human circadian rhythms. International Journal of Chronobiology, 4, 97110. 
Humble, M.B. (2010). Vitamin D, light and mental health. Journal of Photochemistry and Photobiology B: Biology, 101, 142-149.

Hunter, L.P., Rychnovsky, J.D., \& Yount, S.M. (2009). A selective review of maternal sleep characteristics in the postpartum period. Journal of Obstetric, Gynecologic, \& Neonatal Nursing, 38, 60-68.

Insana, S.P., Stacom, E.E., \& Montgomery-Downs, H.E. (2011). Actual and perceived sleep: Associations with daytime functioning among postpartum women. Physiology \& Behavior, 102, 234-238.

Johnson, C.H. (1999). Forty years of PRCs - What have we learned? Chronobiology International, 16, 711-743.

Kanathur, N., Harrington, J., \& Lee-Chiong, T. Jr. (2010). Clinical Chest Medicine, 31, 319-325.

Kennaway, D.J. (2010). Clock genes at the heart of depression. Journal of Psychopharmacology, 24, 5-14.

Kleitman, N. \& Engelmann, T.G. (1953). Sleep characteristics of infants. Journal of Applied Physiology, 6, 269-282.

Koltyn, K.F. \& Schultes, S.S. (1997). Psychological effects of an aerobic exercise session and a rest session following pregnancy. Journal of Sports Medicine \& Physical Fitness, 37, 287-291.

Matsumoto, K., Shinkoda, H., Kang, M.J., \& Seo, Y.J. (2003) Longitudinal study of mothers' sleep-wake behaviors and circadian time patterns from late pregnancy to postpartum. Biological Rhythm Research, 34, 265-278.

McCoy, S.J.B. (2011). Postpartum depression: An essential overview for the practitioner. Southern Medical Journal, 104, 128-132. 
McKenna, J.T., Tartar, J.L., Ward, C.P., Thakkar, M.M., Cordeira, J.W., McCarley, R.W. et al. (2007). Sleep fragmentation elevates behavioral, electrographic and neurochemical measures of sleepiness. Neuroscience, 146, 1462-1473.

McNair, D.M., Lorr, M., \& Droppleman, L.F. (1992). Manual: Profile of Mood States. San Diego, CA: Educational and Industrial Testing Services.

Mendlewicz, J. (2009). Disruptions of the circadian timing systems: Molecular mechanisms in mood disorders. CNS Drugs, 23, 15-26

Mendoza, J., Drevet, K., Pévet, P., \& Challet, E. (2008). Daily meal timing is not necessary for resetting the main circadian clock by calorie restriction. Journal of Neuroendocrinology, 20, 251-260.

Mirick, D.K. \& Davis, S. (2008). Melatonin as a boimarker of circadian dysregulation. Cancer Epidemiology and Biomarkers Prevention, 17, 3306-3313.

Mistlberger, R.E. \& Skene, D.J. (2005). Nonphotic entrainment in humans? Journal of Biological Rhythms, 20, 339-352.

Mollicone, D.J., Van Dongen, H.P.A., Rogers, N.L., Banks, S., \& Dinges, D.F. (2010). Times of day effects on neurobehavioral performance during chronic sleep restriction. Aviation, Space, and Environmental Medicine, 81, 735-744.

Monk, T.H. (1989). A visual analogue scale technique to measure global vigor and affect. Psychiatry Research, 27, 89-99.

Monk, T.H., Buysse, D.J., Reynolds III, C.F., Berga, S.L., Jarrett, D.B., Begley, A.E., et al. (1997). Circadian rhythms in human performance and mood under constant conditions. Journal of Sleep Research, 6, 9-18. 
Monteleone, P. \& Maj, M. (2008). The circadian basis of mood disorders: Recent developments and treatment implications. European Neuropsychopharmacology, 18, 701-711.

Montgomery-Downs, H.E., Insana, S.P., Clegg-Kraynok, M.M., \& Mancini, L.M. (2010). Normative longitudinal maternal sleep: the first 4 postpartum months. American Journal of Obstetrics \& Gynecology, 203, 465e1-7.

Moore, R.Y. (2007). Suprachiasmatic nucleus in sleep-wake regulation. Sleep Medicine, 8, S27S33.

Nishihara, K., Horiuchi, S., Eto, H., \& Uchida, S. (2002). The development of infants' circadian rest-activity rhythm and mothers' rhythm. Physiology \& Behavior, 77, 91-98.

Nyenhuis, D.L., Yamamoto, C., Luchetta, T., Terrien, A., \& Parmentier, A. (1999). Adult and geriatric normative data and validation of the profile of mood states. Journal of Clinical Psychology, 55, 79-86.

Parry, B.L., Meliska, C.J., Sorenson, D.L., Lopez, A.M., Martinez, L.F., Nowakowski, S., et al. (2008). Plasma melatonin circadian rhythm disturbances during pregnancy and postpartum in depressed women and women with personal or family histories of depression. American Journal of Psychiatry, 165, 1551-1558.

Radloff, L.S. (1977). Center for Epidemiological studies depression scale. Applied Psychological Measurement, 1, 385-401.

Righetti-Veltema, M., Conne-Perreard, E., Bousquet, A., \& Manzano, J. (2002). Postpartum depression and mother-infant relationship at 3 months old. Journal of Affective Disorders, 20, 291-306. 
Riemann, D., Konig, A., Hohagen, F., Kiemen, A., Voderholzer, U., Backhaus, J., et al. (1999). How to preserve the antidepressive effect of sleep deprivation: A comparison of sleep phase advance and sleep phase delay. European Archives of Psychiatry and Clinical Neuroscience, 249, 231-237.

Roenneberg, T., Hut, R., Daan, S., \& Merrow, M. (2010). Entrainment concepts revisited. Journal of Biological Rhythms, 25, 329-339.

Roenneberg, T., Kuehnle, T., Pramstaller, P.P., Ricken, J., Havel, M., Guth, A., et al. (2004). A marker for the end of adolescence. Current Biology, 14, 1039-1040.

Ross, L.E., Murray, B.J., Steiner, M. (2005). Sleep and perinatal mood disorders: a critical review. Journal of Psychiatry and Neuroscience, 30, 247-256.

Rotter, J.B. (1966) Generalized expectancies for internal versus external control of reinforcement. Psychological Monographs: General and Applied, 80, 1-28.

Rusting, C.L. \& Larsen, R.J. (1998). Diurnal patterns of unpleasant mood: Associations with neuroticism, depression, and anxiety. Journal of Personality, 66, 85-103.

Samaha, E., Lal, S., Samaha, N., Wyndham, J. (2005). Psychological, lifestyle and coping contributors to chronic fatigue in shift-worker nurses. Journal of Advanced Nursing, 59, 221-232.

Saper, C.B., Scammell, T.E., \& Lu, J. (2005). Hypothalamic regulation of sleep and circadian rhythms. Nature, 437, 1257-1263.

Sato, M., Sakaguchi, T., \& Morita, T. (2005). The effects of exposure in the morning to light of different color temperatures on the behavior of core temperature and melatonin secretion in humans. Biological Rhythm Research, 36, 287-292. 
Schulz, P. \& Steimer, T. (2009). Neurobiology of circadian systems. CNS Drugs, 23, 3-13.

Seyfried, L.S. \& Marcus, S.M. (2003). Postpartum mood disorders. International Review of Psychiatry, 15, 231-242.

Sharma, V.K. (2003). Period responses to zeitgeber signals stabilize circadian clocks during entrainment. Chronobiology International, 20, 389-404.

Shirayama, M., Shirayama, Y., lida, H., Kato, M., Kajimura, N., Watanabe, T., et al. (2003). The psychological aspects of patients with delayed sleep phase syndrome (DSPS). Sleep Medicine, 4, 427-433.

Smith, L. \& Iskra-Golec, I. (2003). Internal locus of control and shiftwork effects. Theoretical Issues in Ergonomics Science, 4, 327-339.

Sohn, C-H. \& Lam, R.W. (2005). Update on the biology of seasonal affective disorder. CNS Spectrums, 10, 635-646.

Stuart, S., Couser, G., Schilder, K., O'Hara, M.W., Gorman, L. (1998). The Journal of Nervous \& Mental Disease, 186, 420-424.

Taillard, J., Philip, P., \& Bioulac, B. (1999). Morningness/eveningness and the need for sleep. Journal of Sleep Research, 8, 291-295.

Terman, J.S., Terman, M., Lo, E-S., Cooper, T.B. (2001). Circadian time of morning light administration and therapeutic response in winter depression. Archives of General Psychiatry, 58, 69-75.

Thomas, K.A. \& Burr, R.L. (2006). Melatonin level and pattern in postpartum versus nonpregnant nulliparous women. Journal of Obstetric, Gynecologic, \& Neonatal Nursing, $608-615$. 
Walker, L.O. \& Cheng, C-Y. (2007). Maternal empathy, self-confidence, and stress as antecedents of preschool children's behavior problems. Journal for Specialists in Pediatric Nursing, 12, 93-104

Wirz-Justice, A. \& Van den Hoofdakker, R.H. (1999). Sleep deprivation in depression: What do we know, where do we go? Biological Psychiatry, 46, 445-453.

Wulff, K. \& Siegmund, R. (2000). Circadian and ultradian time patterns in human behavior: Part 1: Activity monitoring of families from prepartum to postpartum. Biological Rhythm Research, 31, 581-602.

Wyatt, J.K., Ritz-De Cecco, A., Czeisler, C.A., \& Dijk, D. (1999). Circadian temperature and melatonin rhythms, sleep, and neurobehavioral function in humans living on a 20-h day. The American Journal of Physiology-Regulatory, Intergrative and Comparative Physiology, 277, 1152-1163.

Zaharna, M. \& Guilleminault, C. (2010). Sleep, noise and health: Review. Noise \& Health, 12, 64-69.

Zisapel, N. (2001). Circadian rhythm sleep disorders. CNS Drugs, 15, 311-328. 


\section{Appendix A.}

\section{Rotter's Locus of Control Scale}

There are no "right" answers. For each pair of questions, circle a. or b. to indicate the statement with which YOU AGREE the most.

1. a. Children get into trouble because their parents punish them too much.

b. The trouble with most children nowadays is that their parents are too easy on them.

2. a. Many of the unhappy things in people's lives are partly due to bad luck.

b. People's misfortunes result from the mistakes they make.

3. a. One of the major reasons why we have wars is because people don't take enough interest in politics.

b. There will always be wars, no matter how hard people try to prevent them.

4. a. In the long run people get the respect they deserve in this world.

b. Unfortunately, an individual's worth often passes unrecogrized no matter how bard he tries.

5. a. The idea that teachers are unfair to students is nonsense.

b. Most students don't realize the extent to which their grades are influenced by accidental happenings.

6. a. Without the right breaks one cannot be an effective leader.

b. Capable people who fail to become leaders have not taken advantage of their opportunities.

7. a. No matter how hard you try some people just don't like you.

b. People who can't get others to like them don't understand how to get along with others.

8. a. Heredity plays the major role in determining one's personality.

b. It is one's experiences in life which determine what they're like.

9. a I have often found that what is going to happen will happen.

b. Trusting to fate has never tumed out as well for me as making a decision to take a definite course of action.

10. a. In the case of the well prepared student there is rarely if ever such a thing as an unfair test.

b. Many times exam questions tend to be so unrelated to course work that studying is really useless.

11. a. Becoming a success is a matter of hard work, luck bas little or nothing to do with it.

b. Getting a good job depends mairly on being in the right place at the right time.

12. a. The average citizen can have an influence in government decisions.

b. This world is run by the few people in power, and there is not much the little guy can do about it.

13. a. When I make plans, I am almost certain that I can make them work.

b. It is not always wise to plan too far ahead because many things turn out to be a matter of good or bad fortune anyhow.

[4. a. There are certain people who are just no good.

b. There is some good in everybody.

15. a. In my case getting what I want has little or nothing to do with luck.

b. Many times we might just as well decide what to do by flipping a coin. 
16. a. Who gets to be the boss often depends on who was lucky enough to be in the right place first.

b. Getting people to do the right thing depends upon ability, luck has little or nothing to do with it.

17. a. As far as world affairs are concerned, most of us are the victims of forces we can neither understand, nor control.

b. By taking an active part in political and social affairs the people can control world events.

18. a. Most people don't realize the extent to which their lives are controlled by accidental happenings.

b. There really is no such thing as "luck."

19. a. One should always be willing to admit mistakes.

b. It is usually best to cover up one's mistakes.

20. a. It is hard to know whether or not a person really likes you.

b. How many friends you have depends upon how nice a person you are.

21. a. In the long run the bad things that happen to us are bulanced by the good ones.

b. Most misfortunes are the result of lack of ability, ignorance, laziness, or all three.

22. W. With enough effort we can wipe out political corruption.

b. It is difficalt for people to have much control over the things politicians do in office.

23. a. Sometimes I can't understand how teachers arrive at the grades they give,

b. There is a direct connection between how hard I study and the grades I get.

24. a. A good leader expects people to decide for themselves what they should do.

b. A good leader makes it clear to everybody what their jobs are.

25. a. Many times I feel that I have little influence over the things that happen to me.

b. It is impossible for me to believe that chance or luck plays an important role in my life.

26. a. People are lonely because they don't try to be friendly.

b. There's not much use in trying too hard to please people, if they like you, they like you.

27. a. There is too much emphasis on athletics in high school.

b. Team sports are an excellent way to build character.

28. a What happens to me is my own doing.

b. Sometimes I foel that I don't have enough control over the direction my life is taking.

29. a. Most of the time I can't understand why politicians behave the way they do.

b. In the long run the people are responsible for bad government on a national as well as on a local level.

2a

$3 b$

$4 b$

$5 b$

6 a

$7 \mathrm{a}$

$9 \mathrm{a}$

$10 \mathrm{~b}$

$11 \mathrm{~b}$
$12 \mathrm{~b}$

$13 b$

$15 \mathrm{~b}$

$16 a$

$17 \mathrm{a}$

$18 \mathrm{a}$

20a

$21 a$

$22 \mathrm{~b}$
23 a

$25 \mathrm{a}$

$26 \mathrm{~b}$

$28 \mathrm{~b}$

$29 \mathrm{a}$

Total:

High $=$ external

Low $=$ internal 


\section{Morningness-Eveningness Scale}

\section{Read each question carefully and select the most appropriate answer.}

1. If you were entirely free to plan your evening and had no commitments the next day, at which time would you choose to go to bed?

1. $8: 00 \mathrm{pm}-9: 00 \mathrm{pm}$ (5)

2. $9: 00 \mathrm{pm}-10: 15 \mathrm{pm}$ (4)

3. 10:15pm-12:30am (3)

4. 12:30am - 1:45am (2)

5. 1:45am-3;00am (J)

2. You have to do 2 hours physically hard work. If you were entirely free to plan your day, in which of the following periods would you choose to do the work?
1. 8:00am $-10: 00 \mathrm{am}$
(4)
2. 11:00am - 1:00pm
3. $3: 00 \mathrm{pm}-5: 00 \mathrm{pm}$
4. 7:00pm- 9:00pm
(l)

3. For some reason you have gone to bed several bours later than normal, but there is no need to get up at a particular time the next morning. Which of the following is most likely to oecur?

1. Will wake up at the usual time and not fall asleep again. (4)

2. Will wake up at the usual time and doze thereafter.

3. Will wake up at the usual time but will fall asleep again.

4. Will not wake up until later than usual.

4. You have a 2 hour test to sit which you know will be mentally exhausting. If you were entirely free to choose, in which of the following periods would you choose to sit the test?

1. $8: 00 \mathrm{am}-10: 00 \mathrm{am}$ (4)

2. 11:00am-1:00pm (3)

3. $3: 00 \mathrm{pm}-5: 00 \mathrm{pm} \quad(2)$

4. $7: 00 \mathrm{pm}-9: 00 \mathrm{pm} \quad$ (l)

5. If you had no commitments the next day and were entirely free to plan your own day, what time would you get up?

1. $5: 00 a m-6: 30 a m$ (5)

2. 6:30am-7:45am (4)

3. 7:45am-9:45am (3)

4. $9: 45 a m-11: 00$ am (2)

5. 11:00am-12:00pm (l) 
6. A friend has asked you to join him twice a wcek for a work-out in the gym. The best time for him is between $10 \mathrm{pm}-1 \mathrm{pm}$. Bearing nothing else in mind other than how you nomally feel in the evening, how do you think you would perform?

$\begin{array}{ll}\text { 1. Very well } & \text { (1) } \\ \text { 2. Reasonably well } & \text { (2) } \\ \text { 3. Poorly } & \text { (3) } \\ \text { 4. Very poorly } & \text { (4) }\end{array}$

7. One hears about 'morning' and 'evening' types of pcople. Which of these types do you
consider

1. Definitely morning type

2. More a morning than an evening type

3. More an evening than a morning type

4. Definitely an evening type

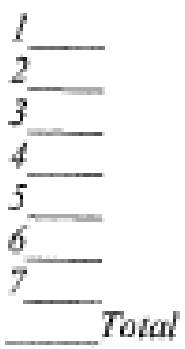

Definitely morning type $\quad$ 28-32

Moderately morning type 23-27

Neither type I6-22

Moderately evening type $\quad$ II-15

Definitely evening type $\quad 6-10$

(Adapted from: Horne JA, Ostberg O. A Self Assessment Questionnaire to Determine Morningmess-Eveningness inhuman Circadian Rhythws. International Journal of Chronobiology $1976 ; 4: 97-110$

\section{John H. \\ HaOn

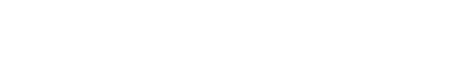

